\title{
Risks to Aquatic Organisms from Use of Chlorpyrifos in the United States
}

\author{
Jeffrey M. Giddings, W. Martin Williams, \\ Keith R. Solomon, and John P. Giesy
}

\section{Introduction}

Effects of chlorpyrifos (CPY) in aquatic ecosystems are dependent on duration and magnitude of exposure and toxicity to individual species. This paper is focused on potential effects of CPY on aquatic organisms and ecosystems based on properties and current uses of CPY (Mackay et al. 2014; Solomon et al. 2014) and probabilities of exposure as determined by measurement in monitoring programs and predictions of simulation models (Williams et al. 2014). Exposures, toxicity, and risks to birds, other terrestrial wildlife, and pollinators are assessed in two additional companion papers (Cutler et al. 2014; Moore et al. 2014). This paper follows the framework for ecotoxicological risk assessment (ERA) developed by the US Environmental Protection Agency (USEPA 1992, 1998, 2004), and builds on a previous assessment of risks posed by CPY in surface waters of North America (Giesy et al. 1999).

Like many risk assessments, the previous assessment of the risk of CPY in surface waters (Giesy et al. 1999) was tiered. Lower tiers of risk assessments incorporate less data and therefore make conservative assumptions when characterizing hazards and

The online version of this chapter (doi:10.1007/978-3-319-03865-0_5) contains supplementary material, which is available to authorized users.

J.M. Giddings $(\triangle)$

Compliance Services International, 61 Cross Road, Rochester, MA 02770, USA

e-mail: jgiddings@ComplianceServices.com

W.M. Williams

Waterborne Environmental Inc., Leesburg, VA, USA

K.R. Solomon

Centre for Toxicology, School of Environmental Sciences, University of Guelph,

Guelph, ON, Canada

J.P. Giesy

Department of Veterinary Biomedical Sciences and Toxicology Centre,

University of Saskatchewan, 44 Campus Dr., Saskatoon, SK S7N 5B3, Canada 
risks. If the criteria for lower tiers do not indicate risk, further refinements of the risk assessment are not needed. This was not the case in the earlier assessment where lower-tier risk criteria were exceeded and potential hazards to aquatic organisms were identified (Giesy et al. 1999). However, these potential hazards were not consistent with the lack of incident reports, such as fish kills, attributable to use of chlorpyrifos in agriculture (Giesy et al. 1999). Refinement of the earlier ERA by the use of Species Sensitivity Distributions (SSDs) and measured concentrations of CPY in surface waters showed that, in almost all locations in the U.S., risks associated with use of CPY in agriculture were either negligible or de minimis (Giesy et al. 1999).

Since the 1999 ERA for CPY was written, there have been refinements in the process of risk assessment and additional data have become available for toxicity and exposures in surface waters. In addition, there have been changes in the labeled uses of CPY (Solomon et al. 2014); most notably, removal of termite control and residential uses of CPY in 2001. The former uses involved large rates of application (with attendant potential for large environmental exposures), and the changes in the labels significantly reduced exposures from relatively uncontrolled uses in urban environments (Banks et al. 2005; Phillips et al. 2007). Availability of additional data and changes in use patterns prompted the reassessment of risks to aquatic organisms from use of CPY in agriculture in the U.S., the results of which are presented here. Since lower-tier assessment had already indicated risk for CPY in surface waters (Giesy et al. 1999), the lower tiers were omitted from this ERA. The current assessment focused on a refined approach that employed SSDs and results of community-level studies in microcosms and mesocosms ("cosms") as points of departure for toxicity, and refined modeling of concentrations in surface waters (Williams et al. 2014, in this volume) to characterize exposures. Concentrations of CPY measured in surface waters were used as a check on the estimates of exposures predicted by use of simulation models (Williams et al. 2014) and as another line of evidence in the ERA.

\section{Problem Formulation for Risk Assessment}

Risk assessments, particularly ERAs, use a formal process of problem formulation (PF) to narrow the focus of the assessment to address key questions and, from these, develop risk hypotheses (USEPA 1998). Several components of the PF have been addressed in detail in companion papers and will only be summarized here.

\subsection{Exposures to Chlorpyrifos}

A conceptual model for exposures to CPY (Fig. 1) was constructed from environmental properties data that are presented in the companion papers (Mackay et al. 2014; Solomon et al. 2014; Williams et al. 2014). As several studies have noted, urban uses were a significant source of historical exposures to CPY in surface water 


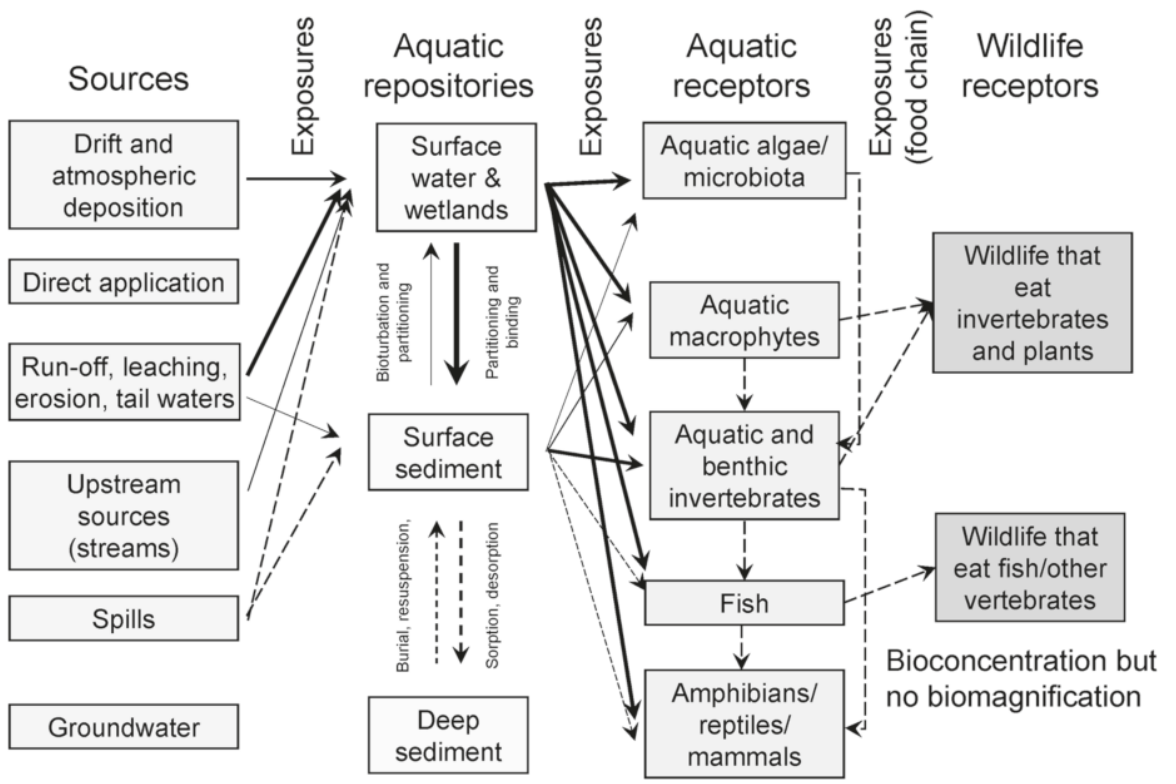

Fig. 1 The conceptual model for exposures of aquatic organisms to chlorpyrifos in surface waters. The weights of the arrows indicate importance of the pathway of exposure

(Banks et al. 2005; Phillips et al. 2007) and sediments (Ding et al. 2010) until label changes occurred in 2001. All current labeled uses of CPY are in agriculture, thus sources from urban uses were omitted from the conceptual model. As is discussed in more detail in Williams et al. (2014), CPY can enter surface waters via several routes (Fig. 1), although some are of lesser importance. CPY is not registered for direct application to surface waters and the relatively large $\mathrm{K}_{\mathrm{OC}}\left(973-31,000 \mathrm{~mL} \mathrm{~g}^{-1}\right.$ Solomon et al. 2014) mitigates against leaching and movement via groundwater. Spills might occur but, because they are episodic and cannot be predicted, the current labeled uses were the focus of this review. The major potential sources for exposures of aquatic organisms are run-off, erosion, and tail waters with lesser inputs via drift of sprays and deposition from the atmosphere (Williams et al. 2014).

CPY adsorbs to surficial sediments in water-bodies, and residues of CPY have been detected in surficial sediments in streams and creeks in areas of use. In a few cases, observed toxicity in sediments collected from agricultural drains, creeks, and rivers in California was linked to the presence of CPY (Phillips et al. 2012; Weston et al. 2012). However, in most locations CPY contributed less to toxicity of sediments than other pesticides such as pyrethroids (Amweg et al. 2006; Ding et al. 2010; Ensminger et al. 2011; Phillips et al. 2006).

CPY is bioconcentrated and/or bioaccumulated into aquatic organisms to a limited extent. Measures of bioconcentration factors (BCFs), bioaccumulation factors (BAFs), and biota-sediment accumulation factors (BSAFs) are relatively small (Mackay et al. 2014). One literature report gave a biomagnification factor (BMF) in 
fish; the value was 0.32 for Aphanius iberus sp. (Varo et al. 2002), which is not indicative of biomagnification. CPY is metabolized by a variety of aquatic organisms and results of studies in model food chain cosms (Metcalf et al. 1971; Metcalf and Sanborn 1975) did not suggest that CPY will biomagnify to a toxicologically significant extent in food chains found in surface waters. Because of the relatively small BCF and BMF values, exposures of terrestrial wildlife that consume aquatic food items were excluded from this risk assessment (Fig. 1). For the same reason, exposures of fully aquatic organisms will mostly be via uptake directly from water, although some dietary exposure to CPY might result from residues adsorbed to food items such as algae, macrophytes, and invertebrates, or from ingested sediment particles. Exposures and risks to terrestrial birds through consumption of granules and terrestrial food items are addressed in a companion paper (Moore et al. 2014).

\subsection{Toxicity of Chlorpyrifos}

The mechanism of toxic action of CPY is through inhibition of acetylcholinesterase (AChE) by the active metabolite, chlorpyrifos oxon (CPYO). The specifics of the mode of action are discussed in greater detail in the companion paper (Solomon et al. 2014). Inhibition of AChE by CPYO is reversible and, in the case of sublethal exposures, recovery of AChE can occur. AChE is a key enzyme in the nervous systems of most animals, and direct effects of CPY will occur at much smaller exposure concentrations than in organisms that lack the target enzyme, such as plants. Insects and crustaceans are generally more sensitive to CPY than are fish or amphibians (Giesy et al. 1999). The primary focus of this ERA is CPY and CPYO. Other metabolites and breakdown products, such as trichloropyridinol (TCP), are much less toxic (USEPA 2008) and are not addressed.

Effects of CPY on animals range from lethality to minor symptoms from which animals recover. Most testing of toxicity of CPY to aquatic animals has used lethality as the measurement endpoint, with results usually expressed as the LC50 or the no-observed-adverse-effect-concentration (NOAEC). Fish are an exception since a number of studies have characterized sublethal and behavioral responses.

\subsubsection{Sublethal Effects on Aquatic Animals}

Several studies have reported effects of CPY on behavior of arthropods and fish. Interpretation of these studies presents difficulties, because it is not always clear if the observed responses are alterations in normal behavior specifically induced by the pesticide or changes in behavior in response to general stress or symptomology of the toxicity. This distinction can be addressed in specifically designed tests such as have been used to assess aversion to ingestion by birds (Moore et al. 2014). In studies of the prawn Macrobrachium rosenbergii, effects on feeding were observed 
at concentrations less than half the 24-h $\mathrm{LC}_{50}$ of $0.7 \mu \mathrm{g} \mathrm{L}^{-1}$ (Satapornvanit et al. 2009). These effects persisted for at least $4 \mathrm{~h}$ after cessation of exposure to CPY, but it is not known if these were truly behavioral responses or symptoms of sublethal poisoning.

A number of studies of sublethal effects of CPY on fish have been conducted, some of which have focused on olfactory perception and others on behavior. Much of the research on effects of CPY and other pesticides on behavior has focused on migratory species of salmon because of their societal importance and the need for migratory species to be able to sense chemicals in water to successfully navigate to breeding waters. Exposure of the olfactory epithelium of Coho salmon (Oncorhynchus kisutch) to $0.7 \mu \mathrm{g} \mathrm{CPY} \mathrm{L}{ }^{-1}$ caused a $20 \%$ loss of sensory function as measured by neurophysiological response to salmonid bile salt and L-serine (Sandahl et al. 2004). Since these studies were conducted in the laboratory, the changes in sensory function were not evaluated at the level of the whole-animal. Several studies have linked effects of CPY on the sensory epithelium and behavior to inhibition of AChE. Working with juvenile Coho salmon (Oncorhynchus kisutch) exposed to CPY at concentrations between 0.6 and $2.5 \mu \mathrm{g} \mathrm{L}{ }^{-1}$, Sandahl et al. (2005) showed that spontaneous swimming rate and food strikes were correlated $\left(\mathrm{r}^{2} 0.58\right.$ and 0.53 , respectively) with inhibition of AChE activity in the brain. Other studies of effects of CPY in the same species showed that thresholds for different behaviors were related to inhibition of AChE (Tierney et al. 2007). Thresholds for effects of CPY on swimming behavior ranged from 20 to $35 \%$ inhibition of AChE. Zebrafish

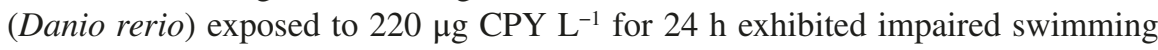
behavior $(\mathrm{p}<0.01)$ and a concentration-response relationship was observed at concentrations greater than $35 \mu \mathrm{g} \mathrm{L}{ }^{-1}$ (Tilton et al. 2011). Similarly, locomotory behavior of mosquito fish, Gambusia affinis, was affected by exposure to $60 \mu \mathrm{g} \mathrm{CPY} \mathrm{L}{ }^{-1}$ for $20 \mathrm{~d}$ (Rao et al. 2005). Although exposures to concentrations of CPY of 100 and $200 \mu \mathrm{g} \mathrm{L}{ }^{-1}$ caused depression of whole-body AChE ( $\approx 60 \%$ of controls) in tadpoles of Rana sphenocephala, there were no effects on swim-speed or vulnerability to predation (Widder and Bidwell 2006).

Most of the reported behavioral responses of fish to CPY were related to inhibition of $\mathrm{AChE}$. These observations are consistent with current understanding of functions of $\mathrm{AChE}$ in the nervous system. It is also not surprising that mixtures of carbamate and organophosphorus pesticides have the same effect as single compounds and that they act additively and sometimes synergistically (Laetz et al. 2009). However, when assessed in the context of actual exposures in the environment, risks are small as the pesticides must co-occur temporally and spatially to cause ecological effects. Even when total potencies of mixtures of insecticides are considered, exposures that inhibit $\mathrm{AChE}$ at concentrations greater than the threshold for effects on behavior rarely occur in key locations for valued species, such as salmon in the Pacific NW (Moore and Teed 2012).

Although effects on behavior due to inhibition of $\mathrm{AChE}$ can be observed in vertebrates, these have not been experimentally related to effects on survival, development, growth, and reproduction of individuals or ecosystem stability or function in a quantitative manner. Therefore, they cannot be incorporated into an ERA at this time. 
Little information has been reported on the effects of CPY or other insecticides on behaviors of other aquatic vertebrates and, to our knowledge, there have been no robust extrapolations of effects on behavior to the endpoints of survival, development, growth and reproduction. For this reason, we excluded behavioral responses from this risk assessment, because it is still uncertain as to how one interprets the data, either for CPY or all other pesticides.

Few studies on aquatic organisms have reported effects on reproduction directly caused by CPY. Chronic exposure of the guppy (Poecilia reticulata) to CPY (commercial formulation) for $14 \mathrm{~d}$ at nominal concentrations of 0.002 and $2 \mu \mathrm{g} \mathrm{L}^{-1}$ resulted in concentration-related reductions in the frequency of reproductive behavior (gonopodial thrusts) in males (De Silva and Samayawardhena 2005). The number of young born per female over the 14-d period was reduced from an average of 27 in the controls to 24 in pairs exposed to $0.002 \mu \mathrm{g} \mathrm{CPY} \mathrm{L}^{-1}$ and 8 in pairs exposed to $2 \mu \mathrm{g} \mathrm{L} \mathrm{L}^{-1}$. Activity of AChE was not reported in this study, so it is difficult to relate these chronic effects to response of $\mathrm{AChE}$ in other studies on behavior or to shorter exposure durations in the field (Williams et al. 2014). Another study on tadpoles of Rana dalmatina (Bernabo et al. 2011) reported that exposures to concentrations of 25 or $50 \mu \mathrm{g} \mathrm{CPY} \mathrm{L}{ }^{-1}$ from Gosner stage 25 to 46 ( $57 \mathrm{~d}$ ) increased the incidence of testicular ovarian follicles (TOFs). This observation was reported at environmentally unrealistic concentrations and is the only report of this response for CPY; no other reports of TOFs in fish or amphibians were found in the literature. There appeared to be no effects of these exposures on mortality or time to metamorphosis. No measurements of AChE activity were reported and the effects on reproduction were not characterized. Because of the paucity of data, we excluded the effects of $\mathrm{CPY}$ on reproduction from this assessment. However, we indirectly addressed the endpoints in some of the cosm studies, where significant changes in reproduction of invertebrates would likely be encompassed in responses at the population level.

\subsubsection{Toxicity of CPY and Temporality of Exposures}

Frequency, duration, and intervals between exposures to CPY will influence responses observed in receptor organisms. These differences in response will result from variations in toxicokinetics and toxicodynamics of CPY in the environment and in individual organisms. The hydraulics of surface waters and variability of inputs from uses and precipitation events shape the types of exposures to pesticides experienced by organisms in flowing waters (Bogen and Reiss 2012). These are further altered by the individual properties of pesticides, such as rates of degradation and/or tendency for partitioning into sediments. As illustrated elsewhere in this volume (Williams et al. 2014), most exposures to CPY in flowing waters are less than $2 \mathrm{~d}$ in duration and are followed by periods of lesser or no exposure. These episodic exposures are typical of what is observed in flowing waters for pesticides in general and are relevant to this risk assessment.

As was pointed out in an earlier risk assessment of CPY (Giesy et al. 1999), exposures via the matrix of the organism (water in this case) are driven by 
thermodynamic processes, such as partitioning into the organism as well as kinetic processes related to rates of diffusion, transport, etc. This means that the critical body burden associated with the threshold of toxicity is not reached until sometime after exposure is initiated. This has been demonstrated for CPY (Giesy et al. 1999) and other organophosphorus insecticides (Bogen and Reiss 2012). The relationship between time of exposure and toxicity is reciprocal, with shorter exposures at greater concentrations resulting in the same level of response as lesser concentrations for longer durations. This reciprocal relationship was demonstrated in studies of effects of CPY on Daphnia magna exposed to CPY for varying durations (Naddy et al. 2000). For example, continuous exposures to $0.25 \mu \mathrm{g} \mathrm{L}^{-1} \mathrm{CPY}$ resulted in $100 \%$ mortality in $5 \mathrm{~d}$, while exposures for $1 \mathrm{~d}$ followed by transfer to clean water resulted in only 17\% mortality, and then only after $16 \mathrm{~d}$ (Naddy et al. 2000). Whether this is the result of a delayed (latent) response or other causes, including regeneration of $\mathrm{AChE}$ activity, is uncertain; however, given the recovery observed in other Crustacea (below), the latter is a more plausible explanation. Where multiple episodic exposures occur, recovery from toxic effects between exposures can affect responses of exposed organisms. This was demonstrated in the greater response of D. magna exposed to the same concentration of CPY for $1 \times 12 \mathrm{~h}$ compared to animals exposed for $2 \times 6 \mathrm{~h}, 3 \times 4 \mathrm{~h}$, or $4 \times 3 \mathrm{~h}$ with a 24-h interval between pulses (Naddy and Klaine 2001). Here, the interval between exposures likely provided time for detoxification and excretion of CPY, recovery of the target enzyme AChE by dephosphorylation ( $\mathrm{k}_{3}$ in Fig. 4 in Solomon et al. 2014), and/or synthesis of new AChE (Naddy and Klaine 2001).

Recovery of AChE inhibited by CPY has been observed in arthropods and fish. After exposure of D. magna to the $24-\mathrm{h} \mathrm{LC}_{50}$ concentration, whole-body activity of $\mathrm{AChE}$ (50\% of unexposed control at time of removal to uncontaminated water) recovered to control activity within $24 \mathrm{~h}$ when animals were moved to clean water (Barata et al. 2004). After exposures of larvae of the midge Kiefferulus calligaster to $0.38,1.02$, or $1.26 \mu \mathrm{g} \mathrm{L}^{-1} \mathrm{CPY}$ for $3 \mathrm{~d}$, concentration-dependent depression of activity of AChE as great as $90 \%$ was observed (Domingues et al. 2009). When transferred to fresh medium for a further $3 \mathrm{~d}$, AChE activity returned to control values. Similar recovery of activity of AChE was observed in the shrimp (Paratya australiensis) exposed to CPY for $96 \mathrm{~h}$ at concentrations from 0.001 to $0.1 \mu \mathrm{g} \mathrm{L} \mathrm{L}^{-1}$ and then moved to clean medium for $48 \mathrm{~h}$ or $7 \mathrm{~d}$ (Kumar et al. 2010). Complete recovery was dependent on exposure concentration and recovery time. Recovery after a 7-d exposure to $0.025 \mu \mathrm{g} \mathrm{L}^{-1}$ occurred in $7 \mathrm{~d}$, but after exposure to $0.1 \mu \mathrm{g} \mathrm{L}^{-1}$, recovery was not complete within $7 \mathrm{~d}$. Whether this recovery resulted from dephosphorylation of $\mathrm{AChE}$ or synthesis of new $\mathrm{AChE}$ is not known. However, it is clear that recovery occurs and that recovery times are of the order of 1 to $\sim \mathrm{d}$.

Studies of fish exposed to CPY suggest that recovery of AChE in fish takes longer than in arthropods. No recovery of brain- or muscle-AChE was observed within a 4-d period in mosquitofish (Gambusia affinis) exposed to $100 \mu \mathrm{g} \mathrm{CPY} \mathrm{L}{ }^{-1}$ for $24 \mathrm{~h}$ (Boone and Chambers 1996). This exposure resulted in $70 \%$ inhibition of these enzymes. In another study of the same species, exposure to $297 \mu \mathrm{g}$ CPY L $\mathrm{L}^{-1}$ for $96 \mathrm{~h}$ resulted in $80 \%$ inhibition of brain-AChE (Kavitha and Rao 2008), but activity had recovered to control levels after $20 \mathrm{~d}$ in clean water. AChE activity in the brain of Nile tilapia, 
Oreochomis niloticus, exposed to $10 \mu \mathrm{g} \mathrm{CPY} \mathrm{L} \mathrm{L}^{-1}$ for $24 \mathrm{~h}$ declined to $47 \%$ of control values but, after transfer to clean water, recovered to $55 \%$ after $7 \mathrm{~d}$ and $63 \%$ after $14 \mathrm{~d}$ (Chandrasekera and Pathiratne 2005). After 14-d exposures of the guppy (Poecilia reticulata) to $0.325 \mu \mathrm{g} \mathrm{CPY} \mathrm{L} \mathrm{L}^{-1}$, activity of whole-body $\mathrm{AChE}$ was $22 \%$ of that in control fish (van der Wel and Welling 1989). Following removal to clean water for a further $14 \mathrm{~d}$, activity of $\mathrm{AChE}$ had recovered to $40 \%$ of that in control fish. Similar observations have been reported for other organophosphorus insecticides. For example, activity of brain-AChE in Atlantic salmon parr (Salmo salar) exposed to formulated fenitrothion (50\% inhibition at initiation of recovery) and transferred to fresh water, recovered to $66 \%$ of control values in $7 \mathrm{~d}$ and $93 \%$ in $42 \mathrm{~d}$ (Morgan et al. 1990). It is not known if AChE recovery rates in fish differ among organophosphorus insecticides having $O$-methyl (fenitrothion) or $O$-ethyl (CPY) substituents, and whether there are models, with which recovery rates can be extrapolated.

If, as is generally suggested (Morgan et al. 1990), recovery of phosphorylated $\mathrm{AChE}$ in fish requires synthesis of new enzyme, rates of recovery would be slow and dependent on rates of metabolism and the physiological and biochemical characteristics of fishes, which appear to be unknown. In the absence of having a model for predicting recovery periods, empirical observations suggest that inter-exposure intervals of the order of 4-8 wk might be required for complete recovery of AChE in fish. This period was incorporated into the ERA (Sect. 4.2).

\subsection{Protection Goals and Assessment Endpoints}

Protection goals and assessment endpoints are strongly linked and do not change as higher tiers or refinements are applied in the ERA. The protection goals applied in this assessment were to protect populations and communities of most aquatic organisms most of the time and at most locations. Specifically, Species Sensitivity Distributions (SSDs) were used (Posthuma et al. 2002) for crustaceans, insects, and fish to calculate the 5th centile (also referred to as the HC5) as a community-focused endpoint. Because of functional redundancy and resiliency, some effects on a small proportion of species can be tolerated in an ecosystem and the 5th centile of these distributions has been shown to be generally protective of ecosystems and the services that they provide (Brock et al. 2006; Maltby et al. 2005). Furthermore, based on results of studies in the field and in cosms, exposures equivalent to the 5 th centile appear to not cause adverse effects on populations or communities. This is due in part to reduced bioavailability compared to exposures of organisms under laboratory conditions, and to more rapid dissipation of CPY under field conditions.

\subsection{Conceptual Models of Effects}

Based on the likely effects of CPY on aquatic animals, a conceptual model for effects was constructed to serve as a guide for developing risk questions and 


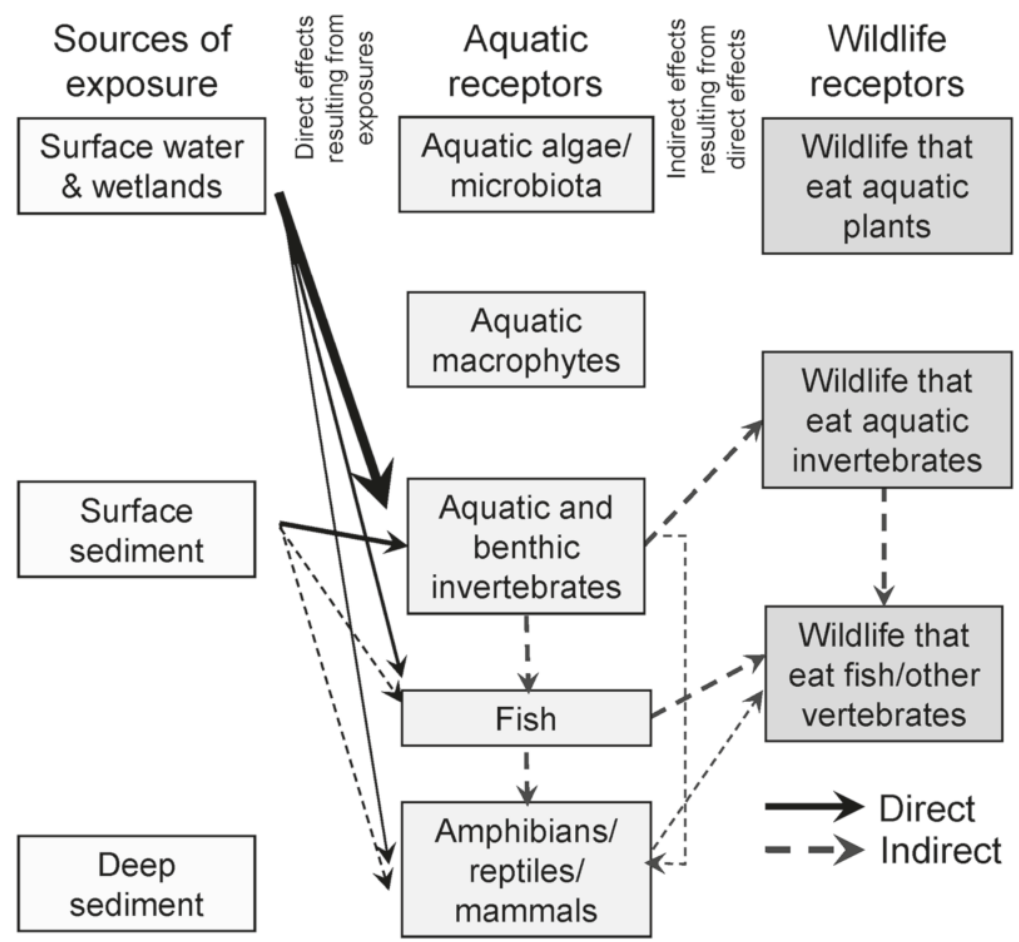

Fig. 2 Conceptual model for effects of chlorpyrifos on aquatic organisms in surface waters. The weights of the arrows indicate importance of the pathway of exposure

hypotheses (Fig. 2). Fish and amphibians are less sensitive to direct effects than crustaceans and insects but they could be affected indirectly via alterations of the food web (Fig. 2). As discussed above, exposure via the food chain was not considered in this ERA.

\subsection{Analysis Plan}

The previous assessment of risks of CPY in surface waters of the U.S. (Giesy et al. 1999) began with a lower-tier deterministic characterization of risk quotients (RQs, also referred to as hazard quotients, HQs) and then advanced through several tiers of refinement to a probabilistic assessment of risks based on comparisons of SSDs to distributions of measured concentrations of CPY in surface waters. Because lower tiers are designed to be conservative and to be applied when few data are available, they are not applicable to CPY, for which there is a wealth of data. Thus, the risk assessment was focused on the upper, more refined, tiers. SSDs were used to characterize acute effects, and these distributions were compared to concentrations predicted by simulation models and concentrations measured in surface waters. 
Episodic exposures of aquatic organisms to CPY in flowing waters were assessed for several scenarios that were selected to represent typical situations (Williams et al. 2014) and reasonable worst-case exposures, relative to times necessary for arthropods and fish to recover during intervals between exposures. In addition, responses and recoveries in microcosms were compared to modeled and measured exposures.

\section{Characterization of Effects}

The toxicity of CPY to non-target organisms was extensively reviewed in 1995 (Barron and Woodburn 1995) and this review was used as an initial reference source. Toxicity data from acute studies in aquatic organisms also were obtained from the USEPA ECOTOX database (USEPA 2007), from studies conducted by Dow AgroSciences, and from the open literature (SI Table 1).

\subsection{Evaluation and Selection of Data}

Studies were assessed for appropriateness by using criteria (Table 1) similar to those recommended for assessing studies for inclusion in the International Uniform Chemical Database (IUCLID) (Klimisch et al. 1997), except that numerical values were assigned to the individual criteria. Scores used to characterize studies are described below, and these were mostly used to assess data from the open literature. Guideline studies conducted under Good Laboratory Practice (GLP) with full Quality Assurance/Quality Control (QA/QC) were given the maximum score unless they had $<5$ concentrations of exposures, the recommended number for guideline studies such as those of OECD.

Applied experimental procedures were scored from 1 to 5 (Table 1). A score of 1 was assigned if the design was inadequately described or incorrect and a 5 if it was complete, such as a guideline study conducted under GLP and with a clear protocol. Examples of factors considered when judging study quality were: incomplete description of the methods, inappropriate designs such as pseudoreplication and lack of appropriate controls, lack of information about test organisms, replicates, or number of test subjects per replicate, lack of an adequate description of the purity or form of the test substance, inappropriate statistical comparisons, lack of details about husbandry of organisms, lack of details on analytical methods, etc.

The use of QA/QC was scored from 1 to 5 (Table 1). If there was full QA/QC, the score was 5. Scores of 2-4 were assigned based on the amount of QC, such as, for example, measurements of exposure concentrations at the start of the study only $($ score $=2)$ or measurements of exposures and other parameters at regular intervals $($ score $=3)$. 


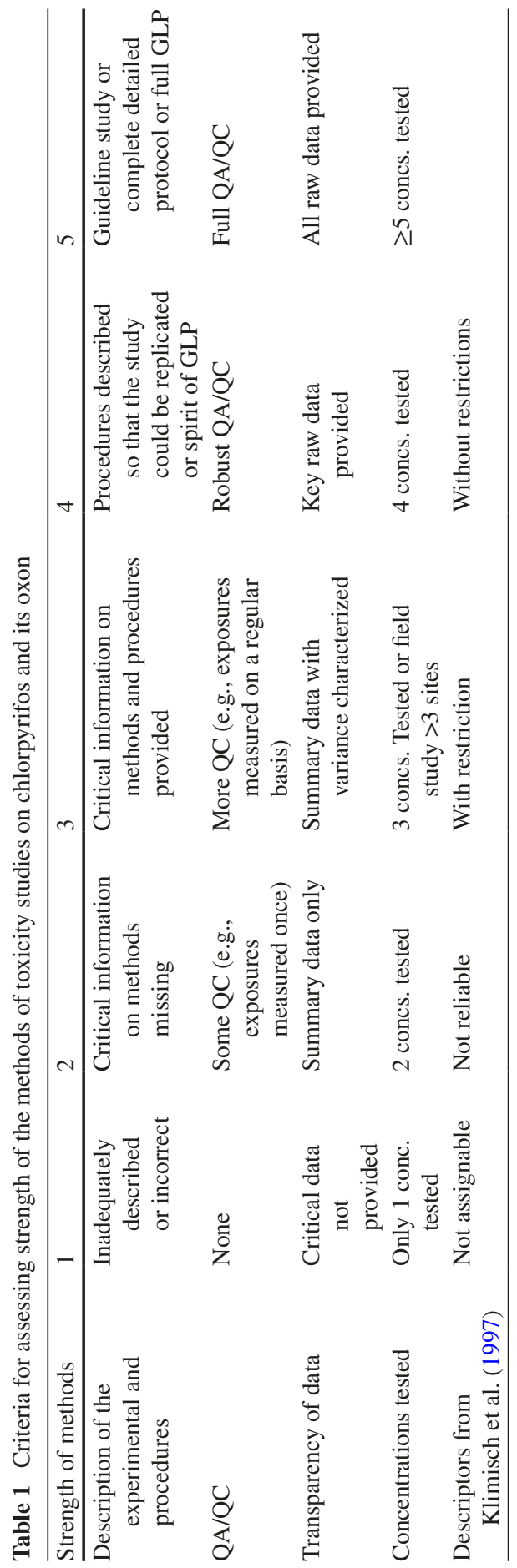


Transparency of data was scored from 1 to 5 (Table 1). If critical data were not provided, a score of 1 was assigned. If full raw data were provided, the score was 5. If data were provided in tables and graphs, intermediate scores were assigned depending on the clarity of the data and the description of variance, etc.

Most concentration-response study guidelines require that five concentrations be used in a toxicity test; therefore, five test concentrations were used to define a maximum score (5). It was recognized that, in some circumstances, the use of fewer concentrations could still provide useful data, particularly if the concentrationresponse curve was steep. These studies were, however, assigned lesser scores.

The overall evaluation of the strength of the methods was obtained from the computed average of the scores. Toxicity data for inclusion in the risk assessment were selected based on the overall score. Guideline and GLP studies with full QA and QC, and studies with scores of $\geq 4$, were preferred. Studies with scores of $<4 \geq 3$ were included as qualified values and those with scores $<3$ were not included.

Additional information was also used to select data for use when multiple results were available for the same species. For example, flow-through exposures were selected over renewal and renewal over static. However, if only data from static exposures were available, they were used with caution. Where several stages of the same species were tested, the more sensitive stage (based on the EC or LC value) was used. For example, data from larval amphibians were selected over embryos, which are generally less sensitive (Richards and Kendall 2002). The details of toxicity data included and excluded from SSDs are indicated in SI Table 1.

Data for saltwater and freshwater, Palearctic and Nearctic, tropical and temperate organisms were not separated, as differences in sensitivity between these groups have been shown to be minimal, and their 5th centile concentrations (HC5s) are not significantly different (Maltby et al. 2005). Data from studies that used the formulated product were included as were those with the active ingredient; however, if data on both formulated and active ingredient were available, only data for the active ingredient were used. If toxicity values for more than one study were available for a species and they were of equal quality, the geometric mean of these values was used to construct the SSD.

For aquatic organisms, the most frequently reported toxicity data were effect concentrations (ECs) that cause some magnitude of effect. For instance, the $\mathrm{EC}_{50}$ is the concentration that causes a $50 \%$ change in a measurement endpoint, such as growth or reproduction. When the effect is mortality, it is expressed as the lethal concentration that causes $50 \%$ mortality in a specified duration of exposure, i.e., 96-h $\mathrm{LC}_{50}$. The HC5, based on acute $\mathrm{LC}_{50}$ values, has been found to be protective of responses to CPY at the ecosystem level (Maltby et al. 2005).

All durations of exposure from 2 to $5 \mathrm{~d}$ were included; durations $>5 \mathrm{~d}$ were excluded from the SSDs. Analysis of the exposure profiles (Williams et al. 2014) showed that concentrations greater than toxicity values were of short duration (median =1 d) and that acute toxicity data were the most appropriate for the assessment. When toxicity values were reported for different periods of exposure, data for the longest period of exposure up to $5 \mathrm{~d}$ were included in the SSDs. Toxicity values excluded from the data set were LOEL, LOEC, NOEL, NOEC, MATC, unspecified 
measures of effect, responses such as behavior, which are difficult to link to survival, development, and reproduction, and data from strains of insects that had been selected for resistance to chlorpyrifos. $\mathrm{LC}$ values such as $\mathrm{LC}_{5}, \mathrm{LC}_{10}, \mathrm{LC}_{90}$, and $\mathrm{LC}_{99}$ were infrequently reported, cannot be combined with $\mathrm{LC}_{50 \mathrm{~s}}$, and were excluded from the assessment.

\subsection{Species Sensitivity Distributions}

As outlined in the Analysis Plan (Sect. 2.5), SSDs were used to characterize the toxicity of CPY to aquatic organisms. Data for different taxa were separated to better assess responses in relation to protection goals which might differ between taxa, for example, invertebrates and fish. Using SSDs to characterize toxicity of CPY is different from using SSDs to develop guidelines and criteria (CCME 2007, 2008).

SSDs were constructed and 5th centiles and their confidence intervals calculated with the aid of the SSD Master Version 3.0 software (CCME 2013). This software is a series of macro statements that are executed in Microsoft Excel. Raw data are entered into a spreadsheet and a cumulative frequency distribution (CFD) is fitted using the plotting positions calculated from the Hazen equation and log-transformed toxicity values to produce an SSD. The data are then fitted to several models (normal, logistic, Extreme Value, and Gumbel) and information on goodness of fit, HC5 and confidence interval for each model is provided. Graphical displays of the SSDs are provided and can be inspected to select those that provide best fit of the data in the region of interest, such as the lower tail of the SSD.

\subsection{Ecotoxicological Profiles by Taxon}

Data were evaluated by taxonomic groups, based on the mode of action and likely sensitivity. These groupings included: plants, crustaceans, insects, fish, amphibians, and other invertebrates. Where insufficient data were available to construct a SSD ( $\geq 8$ species), such as for algae, amphibians, and invertebrates (other than crustaceans and insects), the data are presented in narrative. Results for each taxon are discussed in the following sections.

Plants. The only data on toxicity of CPY to plants were those generated with algae. All of the four species assessed (Table 2) were saltwater algae. Since there were $<8$ data points and only one study met the criterion for inclusion in the analysis, an SSD was not derived. The range of $\mathrm{EC}_{50 \mathrm{~s}}$ for algae was from 138 to $769 \mu \mathrm{g}$ CPY L ${ }^{-1}$, which indicated that algae are relatively tolerant of exposure to chlorpyrifos. Given the mode of action and the lack of a critical mechanism of action or appropriate target site in plants, this is not surprising. Because of this lack of sensitivity, algae were not considered further in the ERA. It is very unlikely that plants 
Table 2 Toxicity values for chlorpyrifos used in this assessment (complete data and codes for the test item, exposure and medium are shown in SI Table 1)

\begin{tabular}{|c|c|c|c|c|c|c|c|}
\hline$\underline{\text { Species }}$ & $\begin{array}{l}\text { Exposure } \\
\text { duration }(\mathrm{d})\end{array}$ & Endpoint & $\begin{array}{l}\mathrm{GM} \\
\left(\mu \mathrm{g} \mathrm{L}^{-1}\right)^{\mathrm{a}}\end{array}$ & $\mathrm{n}$ & $\begin{array}{l}\text { Test } \\
\text { item } \\
\end{array}$ & $\begin{array}{l}\text { Exposure } \\
\text { type }\end{array}$ & Medium \\
\hline \multicolumn{8}{|l|}{$\overline{\text { Algae }}$} \\
\hline Isochrysis galbana & 4 & EC50 (growth) & 138 & 1 & $\mathrm{~F}$ & S & SW \\
\hline $\begin{array}{l}\text { Thalassiosira } \\
\text { pseudonana }\end{array}$ & 4 & EC50 (growth) & 148 & 1 & $\mathrm{~F}$ & $S$ & SW \\
\hline Skeletonema costatum & 3 & EC50 (growth) & 298 & 5 & $\mathrm{~F}$ & S & SW \\
\hline Dunaliella tertiolecta & 4 & EC50 (growth) & 769 & 1 & A & $S$ & SW \\
\hline \multicolumn{8}{|l|}{ Amphibia } \\
\hline Xenopus laevis & 4 & LC50 & 134 & 2 & A & $\mathrm{R}$ & FW \\
\hline $\begin{array}{l}\text { Lithobates clamitans } \\
\quad \text { clamitans }\end{array}$ & 4 & LC50 & 236 & 1 & A & $\mathrm{R}$ & FW \\
\hline Rana dalmatina & 4 & LC50 & 5174 & 1 & A & S & FW \\
\hline \multicolumn{8}{|l|}{ Crustacea } \\
\hline Daphnia ambigua & 2 & LC50 & 0.035 & 1 & A & S & FW \\
\hline Ceriodaphnia dubia & 4 & LC50 & 0.054 & 2 & A & S & FW \\
\hline Gammarus pulex & 4 & LC50 & 0.07 & 1 & A & $\mathrm{F}$ & FW \\
\hline Hyalella azteca & 2 & LC50 & 0.10 & 1 & A & $S$ & FW \\
\hline Moina australiensis & 2 & LC50 & 0.10 & 1 & A & S & FW \\
\hline Gammarus lacustris & 4 & LC50 & 0.11 & 1 & $\mathrm{~F}$ & $\mathrm{~S}$ & FW \\
\hline Daphnia pulex & 3 & LC50 & 0.12 & 1 & A & $\mathrm{R}$ & FW \\
\hline Palaemonetes pugio & 4 & LC50 & 0.15 & 2 & A & $\mathrm{R}$ & FW \\
\hline Neomysis integer & 4 & LC50 & 0.16 & 2 & $\mathrm{~F}$ & $\mathrm{~F}$ & SW \\
\hline Gammarus palustris & 4 & LC50 & 0.19 & 1 & A & $\mathrm{R}$ & SW \\
\hline Daphnia carinata & 2 & LC50 & 0.19 & 3 & A & $S$ & FW \\
\hline $\begin{array}{l}\text { Macrobrachium } \\
\text { rosenbergii }\end{array}$ & 2 & LC50 & 0.30 & 1 & $\mathrm{~F}$ & S & FW \\
\hline Daphnia longispina & 4 & LC50 & 0.30 & 1 & A & $\mathrm{R}$ & FW \\
\hline Paratya australiensis & 4 & LC50 & 0.33 & 1 & A & $\mathrm{R}$ & FW \\
\hline Simocephalus vetulus & 4 & LC50 & 0.50 & 1 & A & $\mathrm{R}$ & FW \\
\hline Daphnia magna & 4 & LC50 & 0.82 & 1 & A & S & FW \\
\hline Amphiascus tenuiremis & 4 & LC50 & 1.47 & 2 & A & $S$ & SW \\
\hline Procambarus sp. & 4 & LC50 & 1.55 & 1 & A & $S$ & FW \\
\hline Gammarus fossarum & 4 & LC50 & 2.90 & 1 & A & $\mathrm{R}$ & FW \\
\hline Orconectes immunis & 4 & LC50 & 6.00 & 1 & A & $\mathrm{F}$ & FW \\
\hline Asellus aquaticus & 4 & LC50 & 8.58 & 1 & A & S & FW \\
\hline Eriocheir sinensis & 4 & LC50 & 30.5 & 4 & $\mathrm{~F}$ & $\mathrm{R}$ & SW \\
\hline $\begin{array}{l}\text { Neocaridina } \\
\text { denticulata }\end{array}$ & 4 & LC50 & 457 & 1 & A & $S$ & FW \\
\hline \multicolumn{8}{|l|}{ Fish } \\
\hline Menidia menidia & 4 & LC50 & 0.53 & 3 & $\mathrm{~F}$ & $\mathrm{~F}$ & SW \\
\hline Leuresthes tenuis & 4 & LC50 & 1.1 & 11 & $\mathrm{~F}$ & $\mathrm{~F}$ & SW \\
\hline Menidia peninsulae & 4 & LC50 & 1.3 & 1 & A & $\mathrm{F}$ & SW \\
\hline Menidia beryllina & 4 & LC50 & 4.2 & 1 & A & $\mathrm{F}$ & SW \\
\hline Fundulus heteroclitus & 4 & LC50 & 4.65 & 1 & $\mathrm{~F}$ & S & SW \\
\hline Pungitius pungitius & 4 & LC50 & 4.70 & 1 & A & $\mathrm{F}$ & FW \\
\hline Atherinops affinis & 4 & LC50 & 4.97 & 2 & $\mathrm{~F}$ & S & SW \\
\hline
\end{tabular}


Table 2 (continued)

\begin{tabular}{|c|c|c|c|c|c|c|c|}
\hline$\underline{\text { Species }}$ & $\begin{array}{l}\text { Exposure } \\
\text { duration }(\mathrm{d})\end{array}$ & Endpoint & $\begin{array}{l}\text { GM } \\
\left(\mu \mathrm{g} \mathrm{L}^{-1}\right)^{\mathrm{a}}\end{array}$ & $\mathrm{n}$ & $\begin{array}{l}\text { Test } \\
\text { item } \\
\end{array}$ & $\begin{array}{l}\text { Exposure } \\
\text { type }\end{array}$ & Medium \\
\hline Poecilia reticulata & 4 & LC50 & 7.2 & 1 & $\mathrm{~A}$ & $\mathrm{R}$ & FW \\
\hline Cyprinus carpio & 4 & LC50 & 8.00 & 1 & $\mathrm{~F}$ & S & FW \\
\hline Oncorhynchus mykiss & 4 & LC50 & 8.49 & 2 & A & $\mathrm{F}$ & FW \\
\hline Gasterosteus aculeatus & 4 & LC50 & 8.5 & 1 & $\mathrm{~A}$ & $\mathrm{~F}$ & FW \\
\hline Lepomis macrochirus & 4 & LC50 & 10 & 1 & A & $\mathrm{F}$ & FW \\
\hline Leuciscus idus & 4 & LC50 & 10 & 1 & A & $\mathrm{R}$ & FW \\
\hline Oncorhynchus clarki & 4 & LC50 & 11 & 3 & $\mathrm{~F}$ & $S$ & FW \\
\hline Aphanius iberus & 3 & LC50 & 18 & 1 & $\mathrm{~F}$ & $\mathrm{R}$ & SW \\
\hline Sander vitreus & 2 & LC50 & 18 & 4 & $\mathrm{~A}$ & S & FW \\
\hline Melanotaenia fluviatilis & 4 & LC50 & 122 & 1 & $\mathrm{~F}$ & $\mathrm{R}$ & FW \\
\hline Pimephales promelas & 4 & LC50 & 207 & 4 & A & $\mathrm{F}$ & FW \\
\hline Salvelinus namaycush & 4 & LC50 & 244 & 1 & $\mathrm{~F}$ & F & FW \\
\hline Oryzias latipes & 2 & LC50 & 250 & 1 & $\mathrm{~A}$ & $\mathrm{R}$ & FW \\
\hline Rutilus rutilus & 4 & LC50 & 250 & 1 & $\mathrm{~A}$ & $\mathrm{R}$ & FW \\
\hline Gambusia affinis & 4 & LC50 & 298 & 1 & A & $\mathrm{R}$ & FW \\
\hline Opsanus beta & 4 & LC50 & 520 & 1 & $\mathrm{~A}$ & $\mathrm{R}$ & SW \\
\hline Ictalurus punctatus & 4 & LC50 & 806 & 1 & A & F & FW \\
\hline Carassius auratus & 4 & LC50 & $>806$ & 1 & A & $\mathrm{F}$ & FW \\
\hline \multicolumn{8}{|l|}{ Insects } \\
\hline Deleatidium sp. & 2 & LC50 & 0.05 & 1 & $\mathrm{~F}$ & $S$ & FW \\
\hline Chironomus riparius & 4 & LC50 & 0.17 & 2 & $\mathrm{~F}$ & NR & FW \\
\hline Atalophlebia australis & 4 & LC50 & 0.24 & 1 & $\mathrm{~A}$ & $\mathrm{R}$ & FW \\
\hline Simulium vittatum & 2 & LC50 & 0.28 & 1 & $\mathrm{~A}$ & $S$ & FW \\
\hline Cloeon dipterum & 4 & LC50 & 0.3 & 1 & $\mathrm{~A}$ & $\mathrm{~F}$ & FW \\
\hline Chironomus dilutus & 4 & LC50 & 0.62 & 2 & $\mathrm{~A}$ & $S$ & FW \\
\hline Anax imperator & 4 & LC50 & 1.98 & 1 & $\mathrm{~A}$ & S & FW \\
\hline Plea minutissima & 4 & LC50 & 1.98 & 1 & A & $S$ & FW \\
\hline Corixa punctata & 4 & LC50 & 2.00 & 1 & $\mathrm{~A}$ & $\mathrm{~F}$ & FW \\
\hline Sigara arguta & 2 & LC50 & 2.16 & 1 & $\mathrm{~F}$ & $S$ & FW \\
\hline Ranatra linearis & 4 & LC50 & 4.48 & 1 & $\mathrm{~A}$ & $S$ & FW \\
\hline Chaoborus obscuripes & 4 & LC50 & 6.6 & 1 & $\mathrm{~A}$ & F & FW \\
\hline Notonecta maculata & 4 & LC50 & 7.97 & 1 & A & $S$ & FW \\
\hline $\begin{array}{l}\text { Xanthocnemis } \\
\text { zealandica }\end{array}$ & 2 & LC50 & 8.44 & 1 & $\mathrm{~F}$ & S & FW \\
\hline Paraponyx stratiotata & 4 & LC50 & 27.2 & 1 & $\mathrm{~A}$ & $S$ & FW \\
\hline Molanna angustata & 2 & LC50 & $>34$ & 1 & A & S & FW \\
\hline Sialis lutariah & 4 & LC50 & $>300$ & 1 & $\mathrm{~A}$ & $S$ & FW \\
\hline \multicolumn{8}{|l|}{ Rotifers } \\
\hline Brachionus calyciflorus & 2 & LC50 & 12,000 & 1 & $\mathrm{~F}$ & S & FW \\
\hline \multicolumn{8}{|l|}{ Mollusks } \\
\hline $\begin{array}{l}\text { Mytilus } \\
\quad \text { galloprovincialis }\end{array}$ & 2 & $\begin{array}{l}\text { EC50 } \\
\quad \text { (develop- } \\
\text { ment) }\end{array}$ & 154 & 1 & A & $S$ & SW \\
\hline Lampsilis siliquoidea & 4 & LC50 & 250 & 1 & $\mathrm{~A}$ & S & FW \\
\hline Aplexa hypnorum & 4 & LC50 & $>806$ & 1 & $\mathrm{~A}$ & $\mathrm{~F}$ & FW \\
\hline
\end{tabular}

${ }^{\mathrm{a}} \mathrm{GM}=$ geometric mean where $\mathrm{n}>1$ 


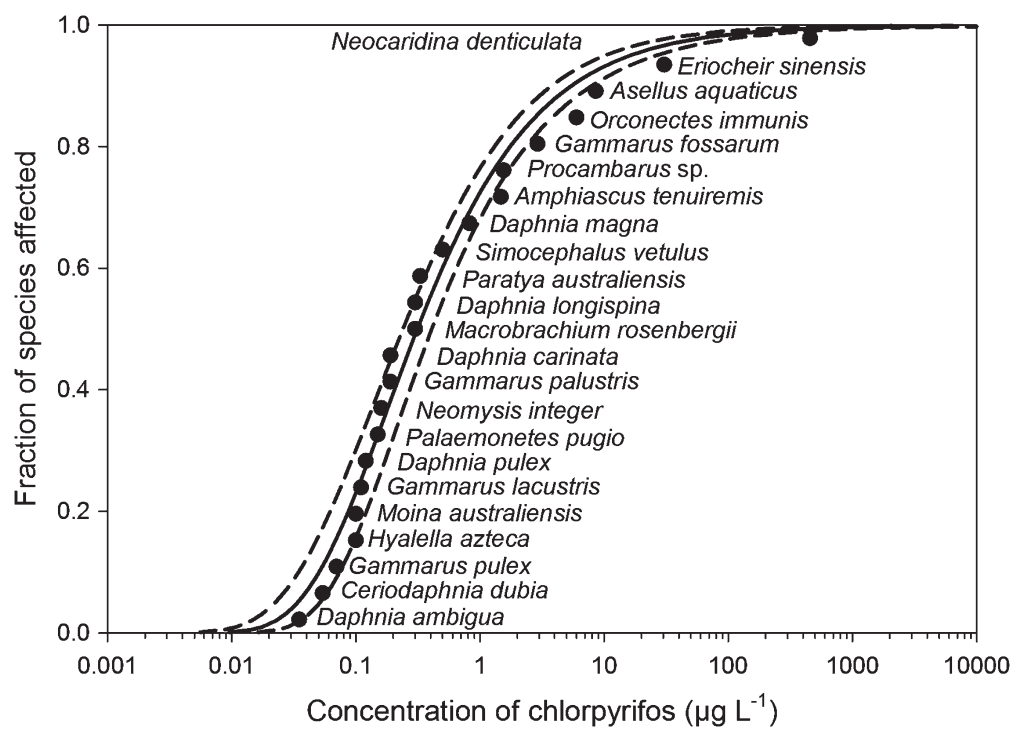

Fig. 3 Species Sensitivity Distribution (SSD) for chlorpyrifos in crustaceans. Solid line is the fitted Gumbel model. Dashed lines represent 95\% confidence interval

would be affected by environmentally-relevant concentrations of CPY and that indirect effects would occur higher in the food web. Thus, protection of these other components of the food web would also be protective of plants in general and phytoplankton in particular.

Crustacea. Data for toxicity of CPY from 23 species of crustaceans met the criteria for inclusion in the analysis (Table 2). The range of $\mathrm{LC}_{50} \mathrm{~S}$ was from 0.035 to $457 \mu \mathrm{g}$ CPY L ${ }^{-1}$. The model for the cumulative frequency distribution (CFD) with the best fit was the Gumbel (SI Table 4, SI Fig. 1) and the SSD is shown in Fig. 3. The HC5 (95\%CI) was $0.034(0.022-0.051) \mu \mathrm{g} \mathrm{CPY} \mathrm{L}{ }^{-1}$ (SI Table 4).

Insects. Toxicity data for CPY from 17 species of aquatic insects met the criteria for inclusion in the analysis (Table 2). The range of $\mathrm{LC}_{50} \mathrm{~S}$ was from 0.05 to $>300 \mu \mathrm{g}$ CPY L ${ }^{-1}$. Two values were reported as "greater than" and were included in the calculations of the ranks for constructing the SSD (Fig. 4). The Extreme Value model gave the best fit for the CFD (SI Table 4), but visual inspection of the plots of the various models showed that the fit in the lower tail was better for the Gumbel model (SI Fig. 1). The lower tail is where exceedences are more likely and, for this reason and for consistency with the other taxa, this model was used. The HC5 (95\% CI) was 0.087 (0.057-0.133) $\mu \mathrm{g}$ CPY L $^{-1}$ (SI Table 4).

Fish. Data for toxicity of CPY from 25 species of fish met the criteria for inclusion in the analysis (Table 2). One value reported as "greater than" was included in the calculations of the ranks for constructing the SSD (Fig. 5). The model that exhibited the best CFD fit was Gumbel (SI Table 4 and SI Fig. 1). The range of $\mathrm{LC}_{50} \mathrm{~S}$ was 


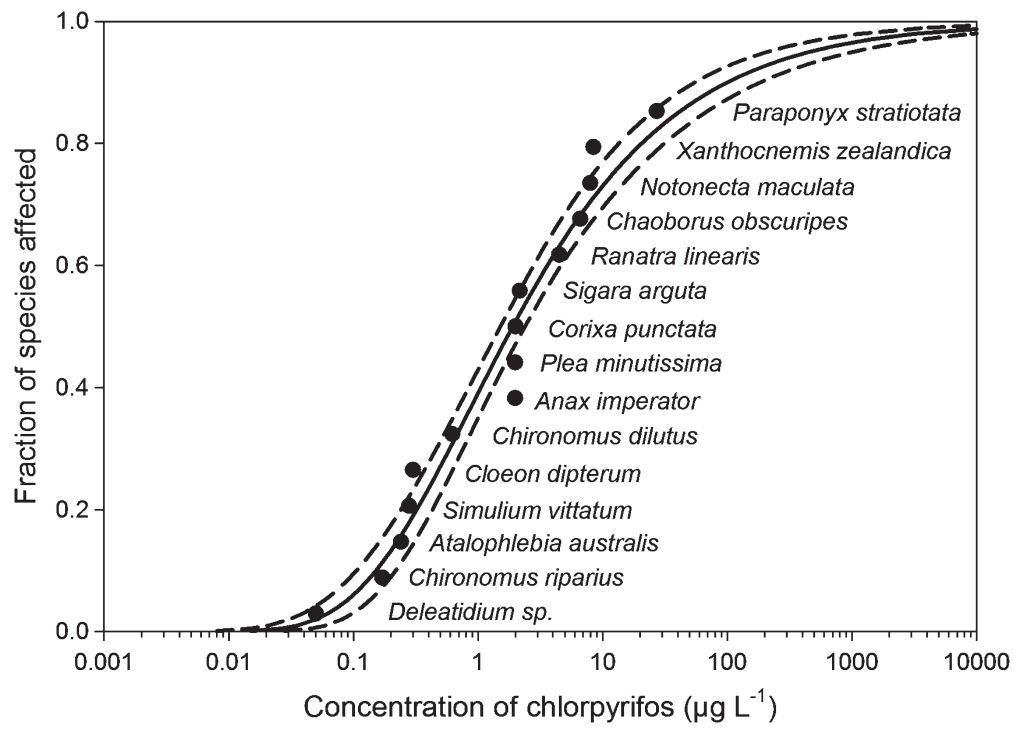

Fig. 4 Species Sensitivity Distribution (SSD) for chlorpyrifos in aquatic insects. Solid line is the fitted Gumbel model. Dashed lines represent 95\% confidence interval. Two species (Molanna angustata and Sialis lutariah) with "greater than" $\mathrm{LC}_{50}$ values were included in the species rankings but not included in the model

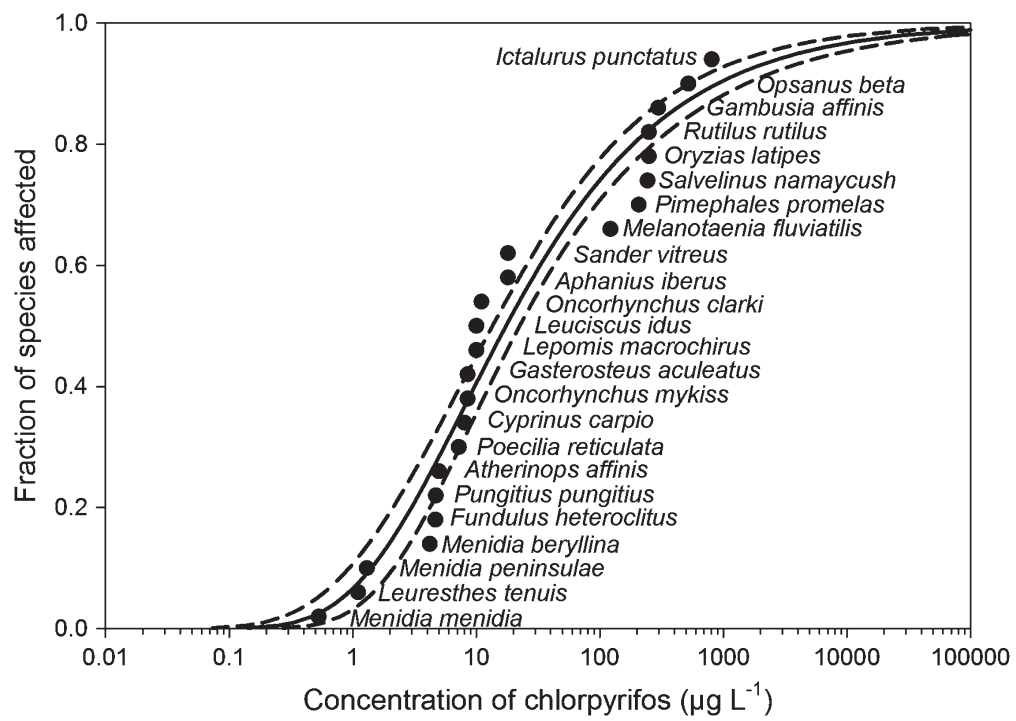

Fig. 5 Species Sensitivity Distribution (SSD) for chlorpyrifos in fish. Solid line is the fitted Gumbel model. Dashed lines represent 95\% confidence interval. One species (Carassius auratus) with a "greater than" $\mathrm{LC}_{50}$ value was included in the species rankings but not included in the model 
Table 3 Toxicity values for chlorpyrifos in benthic organisms

\begin{tabular}{lllllllllll}
\hline Species & Resp. & Test sub. Expos. (d) & Endpoint & $\mu \mathrm{g} \mathrm{kg}^{-1}$ & $\mathrm{n}$ & $\begin{array}{c}\text { Test } \\
\text { item }\end{array}$ & $\begin{array}{c}\text { Expos. } \\
\text { type }\end{array}$ & Inc. Medium \\
\hline $\begin{array}{l}\text { Crustacea } \\
\begin{array}{c}\text { Hyalella } \\
\text { azteca }\end{array}\end{array}$ & Mort & $7-14 \mathrm{~d}$ & 10 & LC50 & 399 & 1 & A & F & Y & FW \\
$\begin{array}{c}\text { Insects } \\
\begin{array}{c}\text { Chironomus } \\
\text { dilutus }\end{array}\end{array}$ & Mort & Larv 3rd 10 & LC50 & 377 & 3 & A & F & Y & FW \\
\hline
\end{tabular}

from 0.53 to $>806 \mu \mathrm{g} \mathrm{CPY} \mathrm{L} \mathrm{L}^{-1}$ and the HC5 (95\%CI) was $0.812(0.507-1.298) \mu \mathrm{g}$ CPY L ${ }^{-1}$ (SI Table 4).

Aquatic stages of amphibians. Of the seven species assessed, only three studies met the QC criteria, and one of these was questionable. The range of $\mathrm{LC}_{50} \mathrm{~S}$ was from 19 to a questionable value of $5,174 \mu \mathrm{g} \mathrm{CPY} \mathrm{L}^{-1}$ (Table 2). Because of the paucity of data, an SSD was not constructed. Larval stages of amphibians have been observed to be less sensitive than fish to a range of chemicals (Weltje et al. 2013), and the toxicity data for fish can be extrapolated to and be protective of amphibians. Therefore, aquatic stages of amphibians were not considered further in the ERA.

Other invertebrates. Toxicity data for four other invertebrates were found (Table 2). The $\mathrm{LC}_{50}$ of $12,000 \mu \mathrm{g} \mathrm{CPY} \mathrm{L}{ }^{-1}$ for Brachionus calyciflorus is consistent with the lack of sensitivity of rotifers to pesticides in general (Brock et al. 2000). Similarly, the three $\mathrm{LC} / \mathrm{EC}_{50}$ values for aquatic mollusks ranged from 154 to $>806 \mu \mathrm{g} \mathrm{CPY} \mathrm{L}{ }^{-1}$, which also is consistent with general lack of sensitivity of this taxon to insecticides (Brock et al. 2000). Because of general lack of sensitivity, these taxa were not considered further in the ERA.

Toxicity of $\mathrm{CPY}$ to benthos. There were few acute toxicity data for benthic organisms. Data from two species met the QC criteria (Table 3). $\mathrm{LC}_{50} \mathrm{~s}$ for Hyalella azteca and Chironomus dilutus were 399 and $377 \mu \mathrm{g} \mathrm{CPY} \mathrm{kg}{ }^{-1}$ (dwt), respectively, or expressed in terms of organic carbon content of the sediment 2,122 and 4,815 $\mathrm{ng} \mathrm{g}^{-1}$ organic carbon (OC), respectively. There were too few data to derive an SSD. Given that the concentration measured in the pore-water at the $\mathrm{LC}_{50}$ was close to the water-only $\mathrm{LC}_{50}$ (Ankley et al. 1994), it was previously concluded (Giesy et al. 1999) that the risk assessment for aquatic organisms could be applied to benthos on the basis of equilibrium partitioning and that risk of CPY to benthos could be extrapolated from organisms in the water column.

Toxicity of $C P Y O$. Insufficient toxicity data on the biologically active metabolite, CPYO, were available (Table 4) to construct an SSD. The $\mathrm{LC}_{50}$ values relevant to risks to surface-water organisms were a $48-\mathrm{h} \mathrm{LC}_{50}$ for D. magna of $1.9 \mu \mathrm{g} \mathrm{CPYO} \mathrm{L}^{-1}$ and 96-h $\mathrm{LC}_{50}$ of $1.1 \mu \mathrm{g} \mathrm{CPYO} \mathrm{L}{ }^{-1}$ in the bluegill sunfish L. macrochirus. The only toxicity value reported for amphibians was in larval Rana boylii, but the reported $\mathrm{LC}_{50}$ value of $>5 \mu \mathrm{g}$ CPYO L ${ }^{-1}$ was from a study that did not meet the criteria for inclusion in the ERA. The $\mathrm{LC}_{50}$ value for CPYO in D. magna was larger than CPY 
Table 4 Toxicity values for chlorpyrifos oxon in aquatic organisms

\begin{tabular}{|c|c|c|c|c|c|c|c|c|c|}
\hline Species & Resp. $^{\text {a }}$ & Test sub. & Expos. (d) & Endpoint & $\mu \mathrm{g} \mathrm{L}^{-1}$ & $\begin{array}{l}\text { Test } \\
\text { item } \\
\end{array}$ & $\begin{array}{l}\text { Expos. } \\
\text { type }\end{array}$ & Inc. & Medium \\
\hline \multicolumn{10}{|l|}{ Coral } \\
\hline $\begin{array}{l}\text { Acropora } \\
\quad \text { millepora }\end{array}$ & Fert & Embryo & 0.125 & EC50 & $>30$ & A & S & Q & SW \\
\hline $\begin{array}{l}\text { Acropora } \\
\quad \text { millepora }\end{array}$ & Meta. & Larva & 0.75 & EC50 & 0.39 & A & $S$ & Q & SW \\
\hline Crustacea & & & & & & & & & \\
\hline $\begin{array}{l}\text { Daphnia magna } \\
\text { Fish }\end{array}$ & Mort. & $<24-\mathrm{h}$ old & 2 & LC50 & 1.9 & A & F & Y & FW \\
\hline $\begin{array}{l}\text { Lepomis } \\
\quad \text { macrochirus }\end{array}$ & Mort. & $46 \mathrm{~mm}$ & 4 & LC50 & 1.1 & A & F & $\mathrm{Y}$ & FW \\
\hline Amphibians & Mort & G32-44 & 4 & I C 50 & $>5$ & $\mathrm{~A}$ & $\mathrm{~S}$ & $\mathrm{~N}$ & FW \\
\hline
\end{tabular}

(0.82 $\mu \mathrm{g} \mathrm{L}^{-1}$, Table 2), while that for L. macrochirus was less than that for CPY (4.2 $\mu \mathrm{g} \mathrm{L}^{-1}$, Table 2). Although CPYO is much more potent than CPY at the target (AChE), the molecule is very labile in aqueous solution (discussed below).

\subsection{Evidence from Microcosms and Mesocosms}

Chlorpyrifos has been the subject of a large number of studies in microcosms and mesocosms (Table 5). Because the distinction between microcosms and mesocosms is primarily semantic, they are referred to jointly as "cosms" in the following discussion. Data from cosms add several types of realism to assessment of the potential effects of chemicals on aquatic organisms (Graney et al. 1995). They allow for more realistic exposure scenarios because factors such as photolysis, microbial degradation and adsorption to aquatic plants and sediments (Giesy and Odum 1980; Graney et al. 1989) are included. Cosms also include dynamic interactions between and among species so that potential "ecosystem-level" effects can be evaluated, including predator-prey interactions in the larger systems (Giesy and Geiger 1980). Early cosm studies of CPY were reviewed by Leeuwangh (1994), Barron and Woodburn (1995), and Giesy et al. (1999). Since the publication of the Giesy et al. review, results of several cosm studies of CPY have featured prominently in comparisons of cosm studies, single-species laboratory toxicity tests, and regulatory benchmarks across classes of insecticides (Brock et al. 2000, 2006; Maltby et al. 2005; van Wijngaarden et al. 2005b). Several newer cosm studies have broadened the scope of conclusions about chlorpyrifos effects on aquatic communities to a wider range of locations and environmental conditions (Daam et al. 2008a, b; López-Mancisidor et al. 2008a, b; van Wijngaarden et al. 2005a; Zafar et al. 2011). The body of evidence from cosm studies is consistent in supporting the conclusion that concentrations of $0.1 \mu \mathrm{g}$ CPY L $\mathrm{L}^{-1}$ or less cause no ecologically significant effects on aquatic communities. 


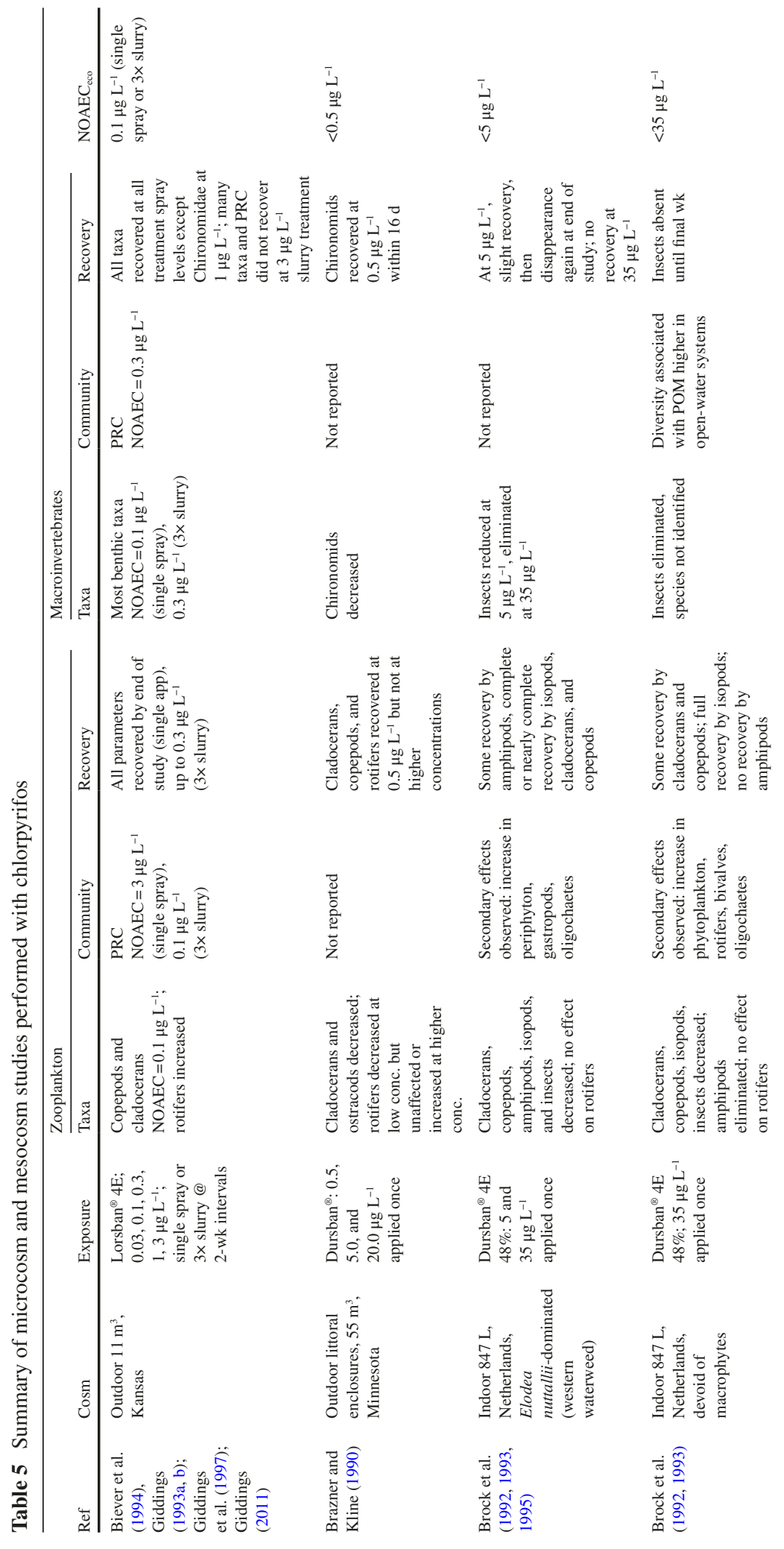




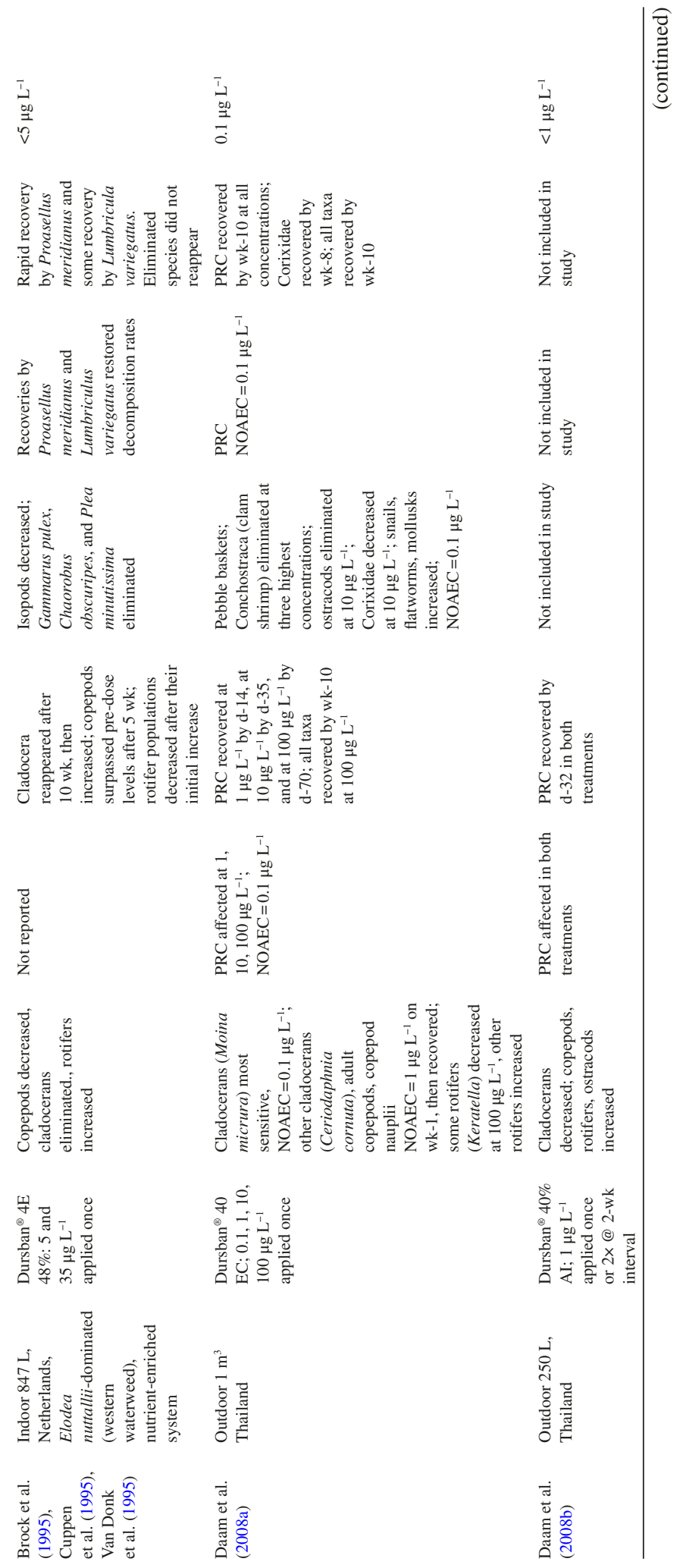




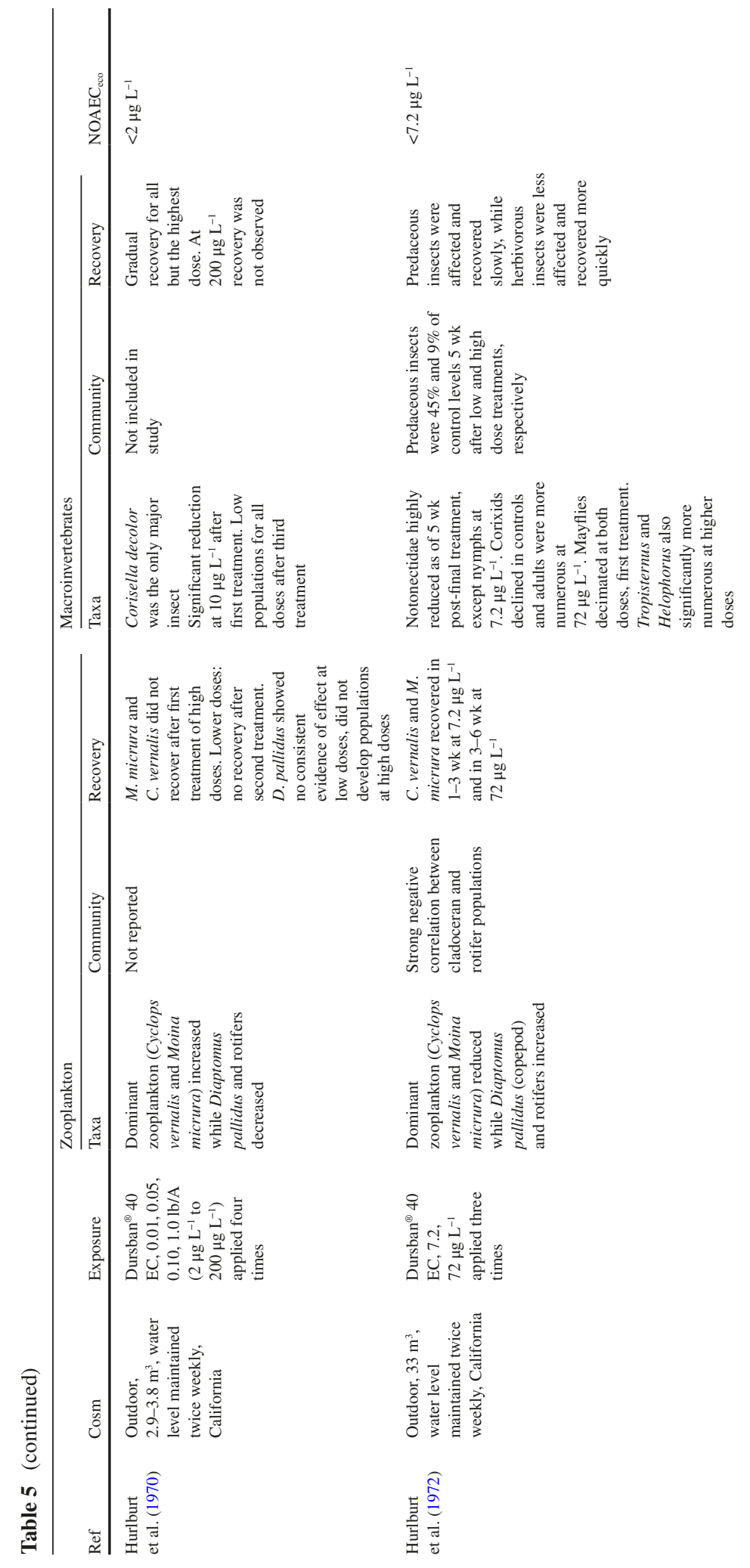




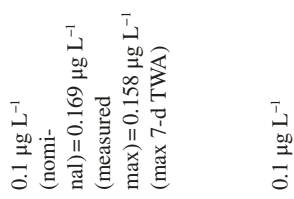

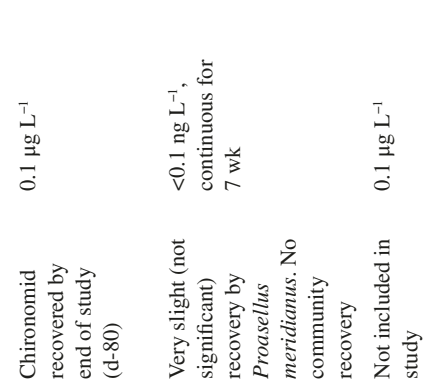

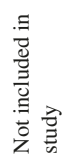

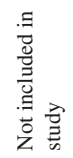

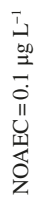

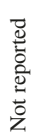

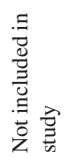

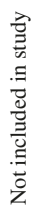

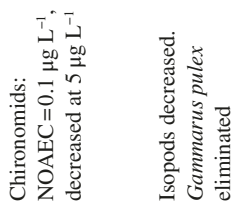

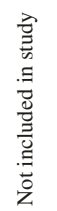

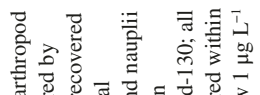

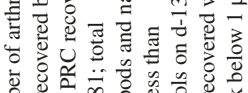

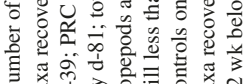

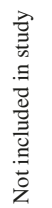

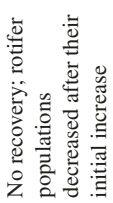

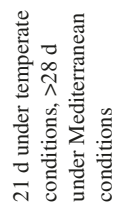

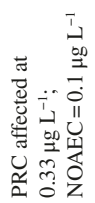

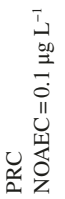

吾

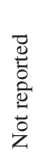

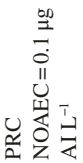

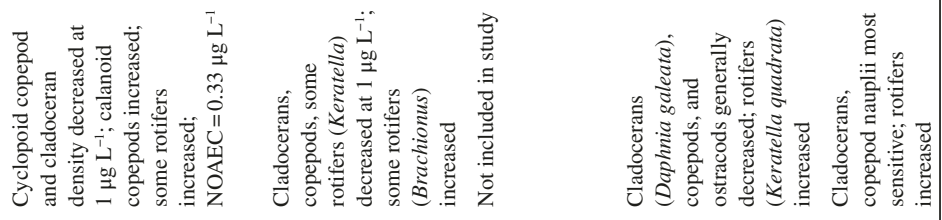

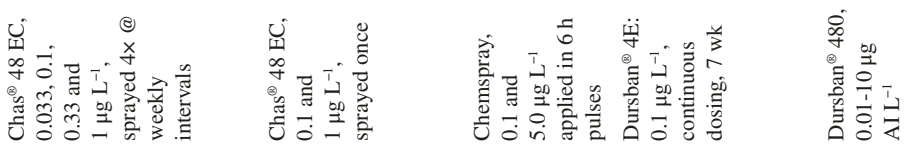

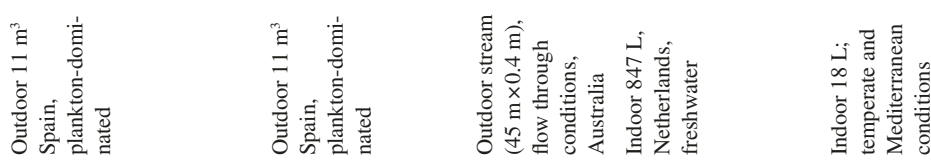

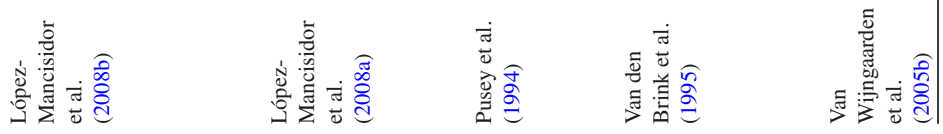




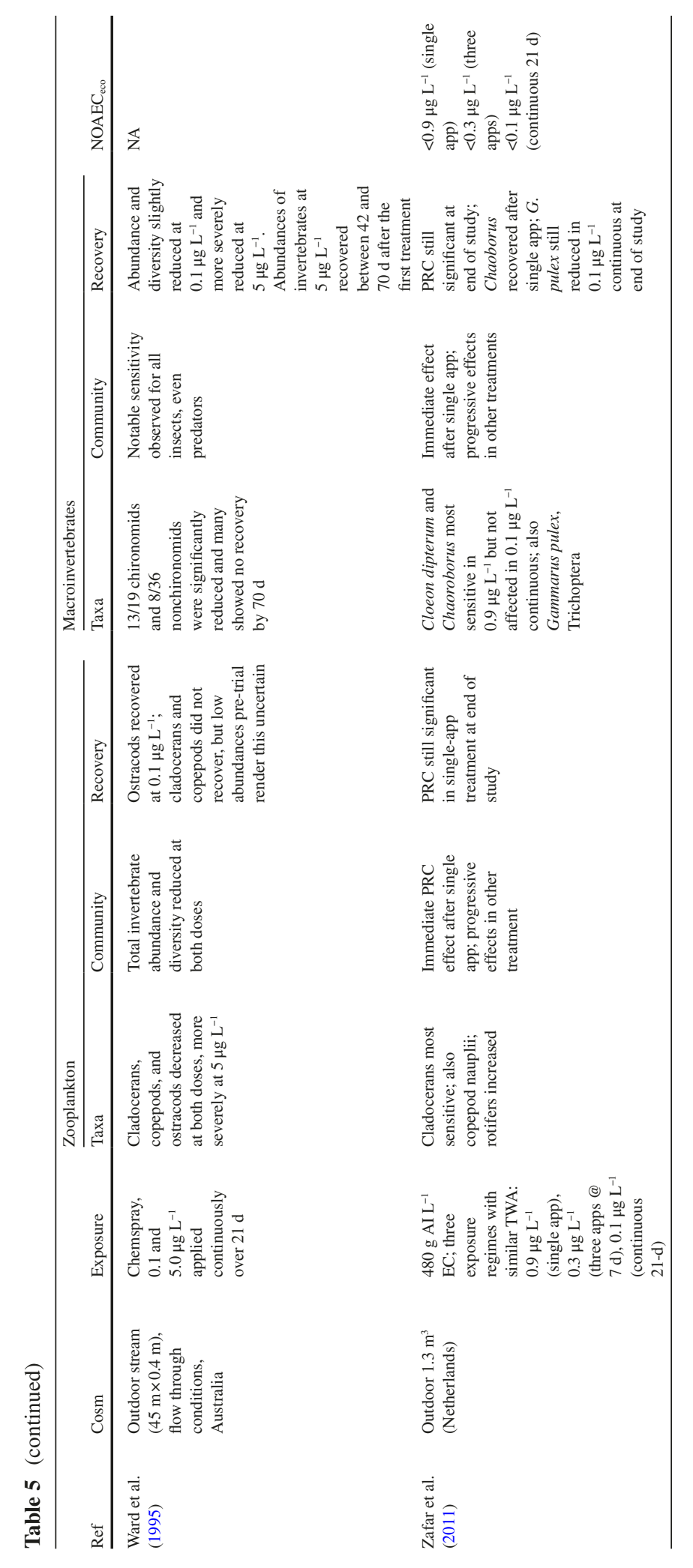


California ponds. Two studies on fates and effects of CPY were conducted in outdoor experimental ponds at Riverside, California (Hurlburt et al. 1970; 1972). In the first study, ponds were sprayed four times at 2-wk intervals at initial concentrations from 2 to $200 \mu \mathrm{g} \mathrm{L}^{-1}$. In the second study, ponds were sprayed three times at 2-wk intervals to produce concentrations of $7.2 \mu \mathrm{g} \mathrm{CPY} \mathrm{L}{ }^{-1}$ and $72 \mu \mathrm{g} \mathrm{L}^{-1}$. In both studies, the dominant zooplankton species, Cyclops vernalis and Moina micrura, were reduced, while Diaptomus pallidus and rotifers (especially Asplanchna brightwelli) increased. The increases in D. pallidus and rotifers were attributed to reduced predation and competition. C. vernalis and M. micrura recovered in 1-3 wk at $7.2 \mu \mathrm{g} \mathrm{L}^{-1}$ and in 3-6 wk at $72 \mu \mathrm{g} \mathrm{L}^{-1}$. Predaceous insects (notonectids and corixids) were affected and recovered slowly, while herbivorous insects were less affected and recovered more quickly. No effects were observed on the mosquitofish (Gambusia affinis).

Minnesota littoral enclosures. In situ enclosures in the littoral region of a pond in Duluth, Minnesota were sprayed once with CPY to produce initial concentrations of 0.5, 5, and $20 \mu \mathrm{g} \mathrm{L}^{-1}$ (Brazner and Kline 1990; Siefert et al. 1989). Cladocerans (five species) and ostracods (Cyclocypris) decreased $4 \mathrm{~d}$ after treatment. Densities of copepods were slightly reduced in treated enclosures but were not significantly less than controls. Rotifers were reduced at $0.5 \mu \mathrm{g} \mathrm{L}-1$, but were unaffected (or increased) at the greater concentrations. Chironomids (the dominant insect group) were reduced $4 \mathrm{~d}$ after treatment; they recovered within $16 \mathrm{~d}$ at $0.5 \mu \mathrm{g} \mathrm{L} \mathrm{L}^{-1}$, but remained less abundant than controls after $32 \mathrm{~d}$ at the greater concentrations. Other insects and the amphipod, Hyalella azteca, were reduced. Snails, planaria, and protozoa were unaffected or increased. Survival of bluegill sunfish (L. macrochirus) decreased at 5 and $20 \mu \mathrm{g} \mathrm{L}^{-1}$. Survival of fathead minnows (Pimephales promelas) was unaffected, but the study authors reported that $P$. promelas growth was reduced due to a reduction in invertebrate abundance. As discussed by Giesy et al. (1999), the data from the study do not support this interpretation, and the effect on growth of $P$. promelas, if real, remains unexplained.

Kansas outdoor cosms. Outdoor pond cosms in Kansas were treated with CPY with initial concentrations of 0.03, 0.1, 0.3, 1, and $3 \mu \mathrm{g} \mathrm{L} \mathrm{L}^{-1}$ (Biever et al. 1994; Giddings 1993a, b; Giddings et al. 1997; Giddings 2011). In separate series of cosms, applications were made as a single surface spray, three CPY-treated slurry applications at 2-wk intervals, and a combination of the two. Results were similar in all three series, and only the single spray treatment will be summarized here.

The total abundance of copepods was reduced for $3 \mathrm{~d}$ at $0.3 \mu \mathrm{g} \mathrm{CPY} \mathrm{L}{ }^{-1}$ (recovery by $\mathrm{d}-15$ ), for $29 \mathrm{~d}$ at $1 \mu \mathrm{g} \mathrm{L}{ }^{-1}$ (recovery by d-43), and for $22 \mathrm{~d}$ at $3 \mu \mathrm{g} \mathrm{L}^{-1}$ (recovery by d-29). No effects were observed at $0.1 \mu \mathrm{g} \mathrm{L}^{-1}$. The calanoid copepod D. pallidus was a notable exception to the general sensitivity of the copepods: at the highest treatment level $\left(3 \mu \mathrm{g} \mathrm{L}^{-1}\right)$ D. pallidus increased soon after the chlorpyrifos application. An increase in D. pallidus after chlorpyrifos treatment was also observed by Hurlbert et al. (1972), who noted that the increase took place only after numbers of $C$. vernalis had decreased. The numbers of cyclopoids, as well as most calanoids other than $D$. pallidus, were also reduced in the Kansas cosms. 
This pattern, observed in studies conducted $20 \mathrm{yr}$ and 2,000 $\mathrm{km}$ apart, implies that (a) D. pallidus is less sensitive than cyclopoids to CPY, and (b) D. pallidus competes with cyclopoids for food, and therefore benefits from reductions in cyclopoid abundance. It has been reported that "the survival and reproduction of D. pallidus were substantially enhanced by the addition of rotifers to a threshold algal diet" (Williamson and Butler 1986). The increase in D. pallidus at $3 \mu \mathrm{g} \mathrm{L}^{-1}$ may therefore have been partly a result of the increase in abundance of rotifers (see below).

The cladocerans were slightly less abundant at $0.3 \mu \mathrm{g} \mathrm{L}^{-1}$ than in controls, but only on d-43. Pronounced effects occurred at $1 \mu \mathrm{g} \mathrm{L}^{-1}$ (recovery by $\mathrm{d}-57$ ) and $3 \mu \mathrm{g} \mathrm{L}^{-1}$ (recovery by d-43). No effects on total numbers of cladocerans were observed at $0.1 \mu \mathrm{g} \mathrm{L}^{-1}$. The most abundant cladocerans were Chydorus sphaericus and Alona sp. C. sphaericus was most sensitive to CPY, while Alona was less sensitive and appeared to benefit from changes that occurred at the greater concentrations.

There were no significant differences in abundance of rotifers among CPY treatment levels on any sample event. The total numbers of the two major rotifer groups, Ploima and Flosculariaceae, were also unaffected by treatment with CPY. Total numbers of zooplankton were not significantly reduced at any concentration on any sample event. The observed reductions in copepods and sensitive cladocerans were offset by increases in rotifers and more tolerant cladocerans.

Benthic insect communities in the cosms were dominated by Diptera and Ephemeroptera. Abundance of Diptera was significantly reduced at 0.3 and $1 \mu \mathrm{g} \mathrm{L}^{-1}$ on d-15 only, and at $3 \mu \mathrm{g} \mathrm{L}^{-1}$ from d-1 through d-29 (recovery by d-42). Treatmentrelated reductions in numbers of Ephemeroptera were found at $0.3 \mu \mathrm{g} \mathrm{L}^{-1}$ (d-1 only), 1 and $3 \mu \mathrm{g} \mathrm{L}^{-1}$ (d-1 and -15). There were no significant differences after d-15. Significant differences in total numbers of benthic insects occurred on d-1 and -15 at 0.3 and $1 \mu \mathrm{g} \mathrm{L}^{-1}$, and from d- 1 through d-29 at $3 \mu \mathrm{g} \mathrm{L}^{-1}$ (recovery by d-42). No effects on Diptera, Ephemeroptera, or total benthic insects were observed at $0.1 \mu \mathrm{g} \mathrm{L}^{-1}$. In terms of invertebrate community structure (based on Principal Response Curve (PRC) analysis) (Giddings 2011) and abundance of sensitive populations within the community, no ecologically relevant effects occurred at $0.1 \mu \mathrm{g} \mathrm{L}^{-1}$.

Australian stream cosms. Two studies in Australia reported effects of CPY on invertebrate communities in large outdoor experimental streams (Pusey et al. 1994; Ward et al. 1995). In the first study, 6-h pulses of CPY were applied at 0.1 and $5 \mu \mathrm{g} \mathrm{L}^{-1}$ and invertebrate community responses were monitored for $80 \mathrm{~d}$. There were no effects at $0.1 \mu \mathrm{g} \mathrm{L} \mathrm{L}^{-1}$. The abundance of chironomids, but not other invertebrate groups, was reduced at $5 \mu \mathrm{g} \mathrm{L}{ }^{-1}$. Invertebrate abundance recovered by the end of the study. In the second study, the same concentrations of CPY were applied continuously for $21 \mathrm{~d}$. Abundance and diversity of invertebrates were slightly reduced at $0.1 \mu \mathrm{g} \mathrm{L}^{-1}$ and more severely reduced at $5 \mu \mathrm{g} \mathrm{L}^{-1}$. Abundances of invertebrates at $5 \mu \mathrm{g} \mathrm{L}^{-1}$ recovered between 42 and $70 \mathrm{~d}$ after the first treatment. Snails became more abundant in the treated streams. 
Dutch ditch cosms. CPY has been the subject of several studies in indoor and outdoor cosms representing Dutch ditches at the Winand Staring Center, The Netherlands. The indoor cosms (Brock et al. 1992; 1993; 1995; Cuppen et al. 1995; van den Brink et al. 1995; Van Donk et al. 1995) were sprayed once, with an initial concentration of $35 \mu \mathrm{g} \mathrm{CPY} \mathrm{L}{ }^{-1}$. Direct effects were observed on cladocerans, copepods, amphipods, isopods, and insects. An algal bloom occurred, as had also been observed in the California ponds (Hurlburt et al. 1970; 1972) and in the Minnesota enclosures (Siefert et al. 1989). The researchers documented the recovery of the cosm-invertebrates as concentrations of CPY declined. Copepods and some cladoceran populations recovered when concentrations of CPY reached $0.2 \mu \mathrm{g} \mathrm{L}^{-1}$; other cladocerans recovered when concentrations fell to $0.1 \mu \mathrm{g} \mathrm{L} \mathrm{L}^{-1}$. Taxa with no recolonization sources (such as insects, amphipods, and isopods) did not recover, but cage studies showed that Asellus aquaticus could survive when concentrations decreased to $1.3 \mu \mathrm{g} \mathrm{L}^{-1}$; and Chaoborus obscuripes, Cloeon dipterum, Gammarus pulex could survive when concentrations reached $0.2 \mu \mathrm{g} C P Y \mathrm{~L}^{-1}$.

The outdoor ditch enclosures were sprayed once with CPY concentrations of 0.1, 0.9, 6, and $44 \mu \mathrm{g} \mathrm{L}{ }^{-1}$ (van den Brink et al. 1996; van Wijngaarden et al. 1996). No effects were observed at $0.1 \mu \mathrm{g} \mathrm{L}{ }^{-1}$. At greater concentrations, numbers of macroinvertebrates were reduced and shifts were observed in the relative abundance of different functional groups (reductions in the proportion of gatherers, increases in the proportions of filter feeders and shredders). Most taxa, other than G. pulex, recovered rapidly at all concentrations. G. pulex could not recover because there was no source of recolonization.

In further studies, macrophyte-dominated outdoor Dutch ditch cosms were treated with CPY under three different exposure regimes: a single application of $0.9 \mu \mathrm{g} \mathrm{L}^{-1}$, three applications of $0.3 \mu \mathrm{g} \mathrm{L}-1$ at 7-d intervals, and continuous application of $0.1 \mu \mathrm{g} \mathrm{L}^{-1}$ for $21 \mathrm{~d}$ using a pump (Zafar et al. 2011). The three exposure regimes were designed to produce similar 21-d time-weighted averages of $0.1 \mu \mathrm{g} \mathrm{L}^{-1}$. Under all exposure regimes, cladocerans and copepod nauplii were the most sensitive taxa of zooplankton, while numbers of rotifers increased. C. dipterum and Chaoborus sp. were the most sensitive taxa of macroinvertebrates. In both the zooplankton and insect communities, effects were observed immediately after the single application of $0.9 \mu \mathrm{g} \mathrm{L}^{-1}$ but occurred more slowly in the other treatments. Overall, effects on both the zooplankton and macroinvertebrate communities were more or less the same under all exposure regimes.

Indoor cosms simulating Mediterranean environments. Indoor, plankton-dominated microcosms were used to compare the responses of aquatic communities to CPY under conditions pertaining to Mediterranean regions (higher temperature and greater amounts of nutrients) with conditions representing cool temperate regions (van Wijngaarden et al. 2005a). CPY was applied once to give concentrations from 0.01 to $10 \mu \mathrm{g} \mathrm{L}^{-1}$ in water of microcosms. CPY dissipated more rapidly under Mediterranean than temperate conditions. As in previous studies, cladocerans and copepod nauplii were among the most sensitive taxa of zooplankton, while numbers of rotifers and adult copepods generally increased as the other groups declined. 
The NOAEC for the most sensitive zooplankton populations and for the zooplankton community was $0.1 \mu \mathrm{g} \mathrm{L}^{-1}$ under both temperate and Mediterranean conditions. The phytoplankton community was altered and phytoplankton chlorophyll increased at $1 \mu \mathrm{g} \mathrm{L}{ }^{-1}$, but only under Mediterranean conditions. Overall, the study supported a community-level NOAEC value of $0.1 \mu \mathrm{g} \mathrm{L}^{-1}$.

Spanish outdoor cosms. Outdoor plankton-dominated $11-\mathrm{m}^{3}$ cosms were treated with single CPY applications of 0.1 and $1 \mu \mathrm{g} \mathrm{L}^{-1}$ (López-Mancisidor et al. 2008b). Cladocerans, copepods, and some rotifers (Keratella sp.) decreased at $1 \mu \mathrm{g} \mathrm{L}^{-1}$; other rotifers (Brachionus sp.) increased. Daphnia galeata, which had been severely reduced, recovered rapidly; Keratella sp. was still reduced on d-99. There were no effects at $0.1 \mu \mathrm{g} \mathrm{L}^{-1}$. In a subsequent study, López-Mancisidor et al. (2008a) sprayed the cosms four times at weekly intervals to produce concentrations of $0.033,0.1$, 0.33 , and $1 \mu \mathrm{g} \mathrm{L}^{-1}$. Population densities of cyclopoid copepods and cladocerans decreased at $1 \mu \mathrm{g} \mathrm{L}^{-1}$, while calanoid copepods and some rotifers increased. Community analysis using PRC indicated significant effects at $0.33 \mu \mathrm{g} \mathrm{L}{ }^{-1}$. All taxa recovered within $12 \mathrm{wk}$ (9 $\mathrm{wk}$ after the final CPY application) except at the highest treatment level $\left(1 \mu \mathrm{g} \mathrm{L}^{-1}\right)$. These studies indicated that CPY caused no effects on zooplankton after single or multiple exposures to $\mathrm{CPY}$ at $0.1 \mu \mathrm{g} \mathrm{L} \mathrm{L}^{-1}$.

Thailand outdoor cosms. In a study in $1-\mathrm{m}^{3}$ outdoor cosms in Thailand treated once $0.1,1,10$, and $100 \mu \mathrm{g} \mathrm{CPY} \mathrm{L}{ }^{-1}$, cladocerans (Moina micrura) were the most sensitive zooplankton taxa, with significant reductions at 1,10 , and $100 \mu \mathrm{g} \mathrm{L} \mathrm{L}^{-1}$ (Daam et al. 2008a). Other cladocerans (Ceriodaphnia cornuta), adult copepods, and copepod nauplii were reduced for $1 \mathrm{wk}$ at $1 \mu \mathrm{g} \mathrm{L}{ }^{-1}$ and then recovered. Some rotifers (including Keratella) decreased at $100 \mu \mathrm{g} \mathrm{L}{ }^{-1}$, while other rotifer species increased. Among macroinvertebrates, Conchostraca (clam shrimp) were eliminated at the three greatest concentrations. Ostracods and corixids were reduced or eliminated at $10 \mu \mathrm{g} \mathrm{CPY} \mathrm{L}{ }^{-1}$. Snails, flatworms, and mollusks increased in abundance. PRC analysis showed that both zooplankton and macroinvertebrate communities were affected at the three greatest concentrations of CPY. Zooplankton communities recovered by d-14 at $1 \mu \mathrm{g} \mathrm{L} \mathrm{L}^{-1}$, d-35 at $10 \mu \mathrm{g} \mathrm{L}^{-1}$, and d-70 at $100 \mu \mathrm{g} \mathrm{L} \mathrm{L}^{-1}$; all taxa of macroinvertebrates recovered by d-70 at all concentrations. Similar studies on the effects of CPY on zooplankton were conducted in 250-L outdoor cosms in Thailand, treated either once or twice (7-d interval) with $1 \mu \mathrm{g} \mathrm{L}{ }^{-1} \mathrm{CPY}$ (Daam et al. 2008b). Cladocerans decreased, while copepods, rotifers, and ostracods increased; $\mathrm{PRC}$ indicated community recovery by d-32 in both treatments. Overall, the Thai cosm studies indicated a NOAEC of $0.1 \mu \mathrm{g} \mathrm{L}{ }^{-1}$.

Conclusions from cosm studies with CPY. Results of cosm studies of CPY summarized above (except the recent studies) were included in analyses by Brock et al. (2000), van Wijngaarden et al. (2005b), Maltby et al. (2005), and Brock et al. (2006), in which the cosm results were compared with single-species toxicity data and regulatory benchmarks for various groups of insecticides. The summarized conclusions of these reviews are consistent with the earlier Giesy et al. (1999) ecological risk assessment, and are:

- Sensitivity of species in cosms is similar to the sensitivity of the same or related taxa in laboratory toxicity tests for single species. For CPY and other acetylcho- 


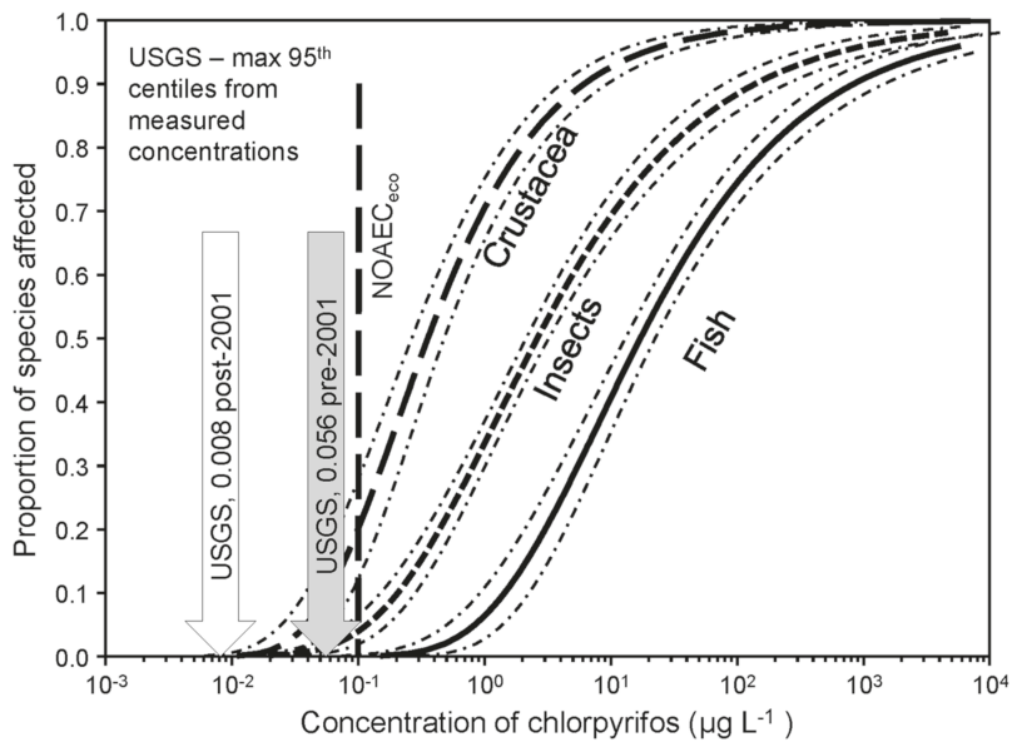

Fig. 6 Comparison of SSDs for 96-h toxicity values for chlorpyrifos and the $\mathrm{NOAEC}_{\text {eco }}$ from cosm studies to greatest annual 95th centiles of concentrations reported by the US Geological Survey from surface waters samples collected before and after 2001. For a more detailed description of the data, see Williams et al. (2014)

linesterase (AChE) inhibitors, Amphipoda, Cladocera, Copepoda, Trichoptera, Ephemeroptera, and Diptera are the most sensitive taxa in cosms, with effects observed at 0.1 - to 1 -times the $\mathrm{LC}_{50}$ of the most sensitive standard test species. Effects on mollusks, annelids, and plants are observed at concentrations 10-100 times greater than the $\mathrm{LC}_{50}$ of the most sensitive species. Most rotifers are unaffected at even greater concentrations.

- The ecosystem-level NOAEC ( $\mathrm{NOAEC}_{\text {eco }}$ ) is the concentration in which "no, or hardly any, effects on the structure and functioning of the studied (model) ecosystem are observed" (Fig. 6, van Wijngaarden et al. 2005b). For CPY, the $\mathrm{NOAEC}_{\text {eco }}$ for a single exposure is $0.1 \mu \mathrm{g} \mathrm{L}{ }^{-1}$. Effects are generally more severe with repeated or chronic exposure, but such exposure patterns are not typical for CPY (Williams et al. 2014). The NOAEC eco falls at the 23rd centile of the SSD for crustaceans, the most sensitive taxon for which data are available (Fig. 6). This implies that use of the HC5 in the risk characterization errs on the side of protection.

- For inhibitors of AChE and other insecticides, sensitive crustaceans and insects in static systems usually recover within $8 \mathrm{wk}$ of a single pulsed exposure below the $\mathrm{LC}_{50}$ of the most sensitive species. For multiple applications, recovery occurs within $8 \mathrm{wk}$ of the last application less than $0.1 \times$ the $\mathrm{LC}_{50}$ (van Wijngaarden et al. 2005b). The extent and rate of recovery in cosms is determined by exposure concentration, life cycle, and ecological factors such as the degree of isolation of the test system from sources of recolonization. 
- Indirect effects are observed only at concentrations that cause pronounced effects on arthropods. The most common indirect effects observed are an increase of algae and an increase of less sensitive herbivores such as rotifers and snails.

- Results in lotic cosms are similar to those in lentic cosms, for CPY and for other insecticides that target AChE.

- Consistent results are obtained from cosm studies conducted in different geographical locations and under different experimental conditions.

\subsection{Reports of Field Incidents in U.S. Surface Waters}

Prior to 2000, there were 44 incidents in a period of $3 \mathrm{yr}$ involving fish-kills and confirmed exposure to CPY, largely associated with improper application of CPY as a termiticide (summarized in Giesy et al. 1999). Not all incidents involving reports of adverse effects of pesticides in humans and the environment are reported to the USEPA, but a search of the US EPA's Aggregate Incident Summary Report by Ingredient revealed no moderate or minor incidents associated with surface waters and CPY or products containing CPY between January 2002 and June 2012 (USEPA 2012a). A total of 1,548 incidents were included in this dataset. However, some incidents were reported in the US EPA's database of Specified Ingredient Incidents (USEPA 2012b). The database contained 666 data records from the U.S. and other locations, and 4 were associated with verified exposure to CPY and kills of fish and/ or invertebrates. All four incidents appeared to be related to misuse and included improper use of CPY as a termiticide in Alabama in June 2002, incorrect aerial application of a mixture of CPY and cyfluthrin in Lavender Canal in California, Feb 2003, and a similar incident on the Boone River, Iowa with a mixture of CPY and pyraclostrobin in Aug 2009. One fish-kill incident was due to a spill or deliberate release of several pesticides, including CPY, in Grape and Core Creeks in North Carolina in May 2003 (Incident \# I014123). Several thousand fish were killed, and CPY was detected at 1.33 and $5.1 \mu \mathrm{g} \mathrm{L}^{-1}$ in Core Creek (along with pebulate and fenamiphos). One sample in Grape Creek contained CPY at $24 \mathrm{~g} \mathrm{~L}^{-1}$ (described as an emulsion), clearly from a major spill or deliberate release. This sample also contained sulfotep $\left(0.51 \mathrm{~g} \mathrm{~L}^{-1}\right)$, diazinon $\left(0.74 \mathrm{~g} \mathrm{~L}^{-1}\right)$, malathion $\left(9.5 \mathrm{~g} \mathrm{~L}^{-1}\right)$, and fenamiphos $\left(1.6 \mathrm{~g} \mathrm{~L}^{-1}\right)$. All incidents were linked to misuse, and there was no indication that normal use of CPY in agriculture has resulted in fish kills.

\section{Characterization of Risks}

Where sufficient data were available, such as for surface waters, risks posed by CPY to aquatic organisms were characterized by comparison of measured and predicted concentrations to SSDs of acute toxicity values. For sediments, where fewer toxicity data were available, simple quotients of exposure concentrations to single toxicity values (risk quotients, RQs) were utilized. 
Table 6 Risk quotients for maximum 95th centile measured concentrations of CPY in surface waters of the U.S. before and after 2001

\begin{tabular}{llll}
\hline Taxon & Crustacea & Insects & Fish \\
\hline HC5 $\left.(\mu \mathrm{g} \mathrm{L})^{-1}\right)$ & 0.034 & 0.091 & 0.820 \\
RQ for greatest annual 95th centile pre-2001 $\left(0.056 \mu \mathrm{g} \mathrm{L}^{-1}\right)^{\mathrm{a}}$ & 1.65 & 0.64 & 0.07 \\
RQ for greatest annual 95th centile post-2001 $\left(0.008 \mu \mathrm{g} \mathrm{L}^{-1}\right)^{\mathrm{a}}$ & 0.24 & 0.09 & 0.01 \\
\hline
\end{tabular}

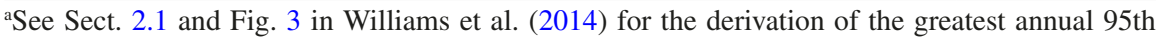
centile concentrations

\subsection{Risks from Measured Exposures}

Risks for CPY in surface waters. There is a relatively large database of measured concentrations of CPY in surface waters (see detailed characterization in Sect. 3.1 in Williams et al. 2014). In almost all of these data sets, frequency of sampling was too small to allow exposures to be characterized as 96-h time-weighted-mean concentrations for direct comparison to $96-\mathrm{h}$ toxicity values. However, comparisons in relation to changes in the use of CPY were possible. The greatest annual 95th centiles of concentrations measured in surfaces waters by the US Geological Survey before and after the introduction of new labels in 2001 clearly shows the reductions in exposures and risks that resulted from the changed use pattern (Fig. 6 and Table 6). Based on 95th centiles and the HC5, risks for fish in either period were small. An extensive review of the toxicity screening data from 2004 to 2009 in samples of surface waters of the Central Valley of California (Hall and Anderson 2012) confirmed that the reductions in concentrations of CPY after 2001 (see Sect. 4 in Williams et al. 2014) were reflected in reductions in the frequency of detection of toxicity mediated by CPY.

Risks for CPY in sediments. The toxicity of CPY in sediments in areas of intensive use, has infrequently been reported in studies conducted recently (Sect. 2.1). Comparison of the 10-d $\mathrm{LC}_{50}$ toxicity values for H. azteca and C. dilutus (Table 3) to the greatest concentration $\left(58.6 \mu \mathrm{g} \mathrm{kg}^{-1}\right)$ measured in sediments (Sect. 3.2 in Williams et al. 2014) gave RQs of 0.15 and 0.16 for the two species. These RQs are only slightly above the Level of Concern for non-endangered species (USEPA 2004) and are consistent with toxicity testing of sediments from areas of intensive use since 2000 (Sect. 2.1).

Risks from CPYO. As discussed in a companion paper (Solomon et al. 2014), CPYO is formed from CPY in the environment and in vivo but has seldom been detectable in surface waters (see Sect. 4 in Williams et al. 2014). The National Water Quality Assessment (NAWQA) database included results of 7,098 analyses for CPYO in surface water samples between 1999 and 2012 (NAWQA 2012). CPYO was detected in 16 samples (detection rate of $0.23 \%$ ), and the greatest estimated concentration (i.e., $>$ LOD but $<\mathrm{LOQ}$ ) was $0.0543 \mu \mathrm{g} \mathrm{CPYO} \mathrm{L}{ }^{-1}$. Similar results were found in the National Stream Quality Accounting Network (NASQAN) database (NASQAN 2012), 
where the rate of detection for 2,025 analyses of surface water between 2001 and 2012 was $0.44 \%$, and the greatest estimated concentration was $0.0356 \mu \mathrm{g} \mathrm{CPYO} \mathrm{L}{ }^{-1}$. Databases of pesticide concentrations in surface waters of California (288 analyses, CDPR 2012) and Washington State (964 analyses, WDOE 2012) contained no detections for CPYO. In a study of pesticides in surfaces waters at various elevations above the Central Valley of California (LeNoir et al. 1999), CPYO was detected at concentrations ranging from 0.024 to $0.037 \mu \mathrm{g} \mathrm{CPYO} \mathrm{L}^{-1}$ as compared to $\mathrm{CPY}$ which ranged from 0.089 to $0.124 \mu \mathrm{g} \mathrm{CPY} \mathrm{L} \mathrm{L}^{-1}$ at the same locations. Thus, the frequency of detection was small and the concentrations, when measurable, also were small.

Risks from measured concentrations of CPYO were all small. The RQ for the greatest measured concentration of CPYO in surface waters $\left(0.054 \mu \mathrm{g} \mathrm{L}^{-1}\right)$ and the $\mathrm{LC}_{50}$ of $1.1 \mu \mathrm{g} \mathrm{L}^{-1}$ for the most sensitive freshwater (FW) organism tested (L. macrochirus) was 0.049 , which is below the level of concern (LOC) for highly valued species (USEPA 2004).

The small estimated risks from CPYO are supported by several lines of evidence. CPYO is formed from CPY in the atmosphere and is detected in air near sites of application and at more distant locations (see discussion in Mackay et al. 2014). Because CPYO is more polar than CPY (log KOW of 2.89 vs. 5, Tables 5 and 6 in Mackay et al. 2014) it would be expected to partition into precipitation and accumulate to a greater extent than CPY in surface waters. However, this does not occur; for example, LeNoir et al. (1999) showed that CPYO was detected in water at smaller concentrations than CPY, the opposite of those in air sampled at the same locations. The most likely reason for this is the greater rate of hydrolysis of CPYO compared to CPY with half-lives of $13 \mathrm{~d}$ vs. 30-50 d, respectively (Tables 7 and 6 in Mackay et al. 2014). Since CPYO is more polar than CPY (Mackay et al. 2014), it would not be expected to be taken up into and accumulate in organisms as much as CPY. Finally, because CPYO is the active toxic form of CPY and is transformed in vivo, the toxicity of CPYO would be implicitly included in toxicity testing in the laboratory and cosms where animals are exposed to CPY. For all these reasons, environmental risks from CPYO were smaller than those for CPY. Therefore, a separate and detailed risk assessment was not required.

\subsection{Risks from Modeled Exposures to CPY}

Probabilistic analysis of risks. The higher-tier modeling of CPY concentrations in surface waters for three scenarios of intensive use and vulnerability to runoff and contamination of surface waters (Sect. 6.2 in Williams et al. 2014) provided frequency distributions of annual maximum 96-h time-weighted mean concentrations. These values could then be compared to distributions of 48- to 96-h toxicity values from the SSDs (Sect. 3.2) using probabilistic approaches. To characterize the risks graphically, these values were used to construct joint probability curves (JPCs, ECOFRAM 1999; Giesy et al. 1999). Reference lines proposed for interpretation of JPCs (Moore et al. 2010) were added to the graphs. 


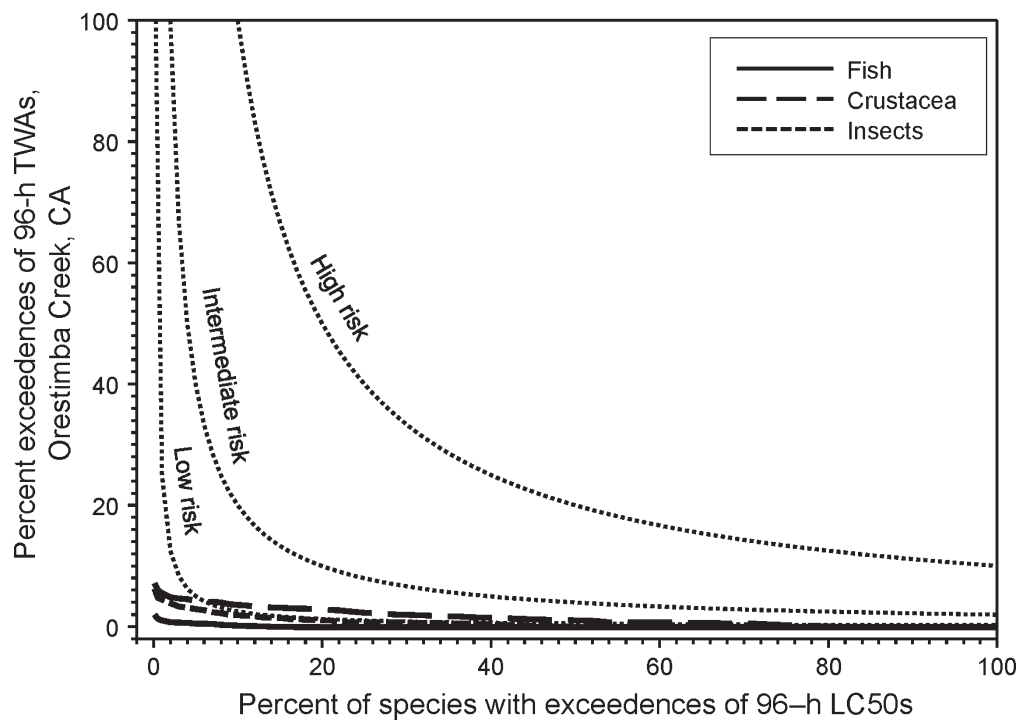

Fig. 7 Joint probability curves for estimated 96-h time-weighted average (TWA) concentrations of chlorpyrifos in Orestimba Creek, CA modeled from Jan 1, 2000 to Dec 31, 2009 and species sensitivity distributions for fish, Crustacea, and insects

The JPCs for the concentrations modeled in Orestimba Creek, CA (Fig. 7) showed that fish and insects were at de minimis risk. The line for crustaceans was slightly above the reference line for low risk, indicating that some species of crustaceans are at low (but not de minimis) risk of adverse effects in this use scenario.

The JPC for concentrations modeled in another focus-scenario, Cedar Creek, MI (Fig. 8) indicated de minimis risk for crustaceans, insects, and fish. The modeled concentrations in the other focus-scenario, Dry Creek, GA were smaller than those in Cedar Creek, MI (Table 8 in Williams et al. 2014), hence, these risks also were de minimis (JPC not shown). Overall, the probabilistic analyses of these data suggest that risks from direct effects of CPY on fish are de minimis in all areas of use. In most areas of use, as exemplified by the modeling of concentrations in Cedar Creek, MI and Dry Creek, GA, risks to insects and crustaceans will be de minimis as well. Low risk is also predicted for crustaceans in Orestimba Creek, CA, an intensive-use scenario that reasonably exemplifies the worst-case.

There were insufficient toxicity data for CPY in sediment to conduct a probabilistic assessment of risk. However, comparison of the $10-\mathrm{d} \mathrm{LC}_{50}$ toxicity values for H. azteca and C. dilutus (Table 3) to the maximum modeled values of 22.2, 0.067, and $0.074 \mu \mathrm{g} \mathrm{kg}^{-1}$ resulted in RQs of $0.06,<0.001$, and $<0.001$ for Orestimba Creek, Cedar Creek, and Dry Creek, respectively. The RQs for Cedar Creek and Dry Creek are well below the Level of Concern for all species. The RQ for Orestimba Creek is slightly greater than the Level of Concern (0.05; EPA 2004) for endangered and threatened (listed) invertebrates, but below the Level of Concern for other (nonlisted) species. 


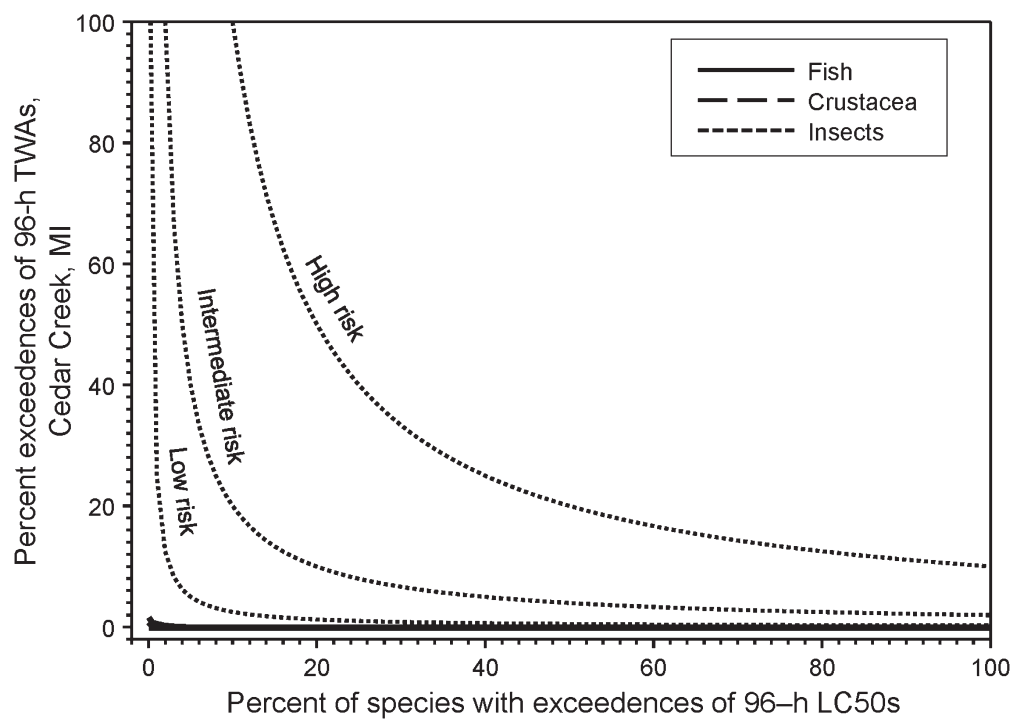

Fig. 8 A joint probability curve for estimated 96-h time-weighted mean concentrations of chlorpyrifos in Cedar Creek, MI modeled from Jan 1, 1961 to Dec 31, 1990. For details of the modeling of exposures, see Williams et al. (2014)

Risks from repeated exposures to $C P Y$. The risks of CPY were further evaluated by considering the duration of exposure and the time between exposures that were predicted by SWAT for watersheds in Michigan, Georgia, and California. The analysis was conducted using the RADAR program (ECOFRAM 1999; Williams et al. 2014). RADAR analyzes the daily time-series of exposure estimates to identify events in which concentrations exceed a pre-defined threshold, calculate the duration of each event, and determine the time between events (recovery time). The NOAECeco from the cosm studies, $0.1 \mu \mathrm{g} \mathrm{L}^{-1}$, was used as the threshold in this analysis. The full results are presented in SI Appendix E of Williams et al. (2014). No events occurred in the Georgia watershed, and none in the Michigan watershed when the 28-d half-life was used. With a 96-d half-life, there were three events in the Michigan watershed, all of 1-d duration and with at least 1,240 d between events. The short event durations and long intervals between events imply that no exposures in the Michigan watershed would result in ecologically significant effects.

Over the 10-yr simulation in the California watershed, there were 10 events (28-d half-life) or 35 events (96-d half-life), in which concentrations exceeded $0.1 \mu \mathrm{g} \mathrm{L}^{-1}$. The minimum and median event durations in the California watershed were $1 \mathrm{~d}$ for both half-lives, and the maximum event durations were $11 \mathrm{~d}$ and $15 \mathrm{~d}$ using the 28- $\mathrm{d}$ and 96-d half-lives, respectively. Recovery times ranged from 1 to $>1,892 \mathrm{~d}$. Using either half-life, recovery times in half of the events were greater than $14 \mathrm{~d}$, long enough for toxicodynamic recovery from $\mathrm{AChE}$ inhibition in crustaceans and insects (Sect. 2.2). About one-third of these events had recovery times greater than $56 \mathrm{~d}$, long enough for toxicodynamic recovery in fish (Sect. 2.2) and for ecological 
recovery in cosms (Sect. 3.4). Only three or four events (for the 96-d and 28-d half-lives, respectively) had durations of $4 \mathrm{~d}$ or greater and recovery times less than $56 \mathrm{~d}$. These results suggest that ecologically significant single and repeated exposure events were rare, even in the high-exposure California scenario.

\section{Conclusions}

This ecological risk assessment of CPY and its oxon CPYO built upon a previous assessment (Giesy et al. 1999) and was refined to address changes in the labeled uses, different use patterns, and new toxicity data. Exposure data were taken from Williams et al. (2014), which characterizes measured and modeled concentrations of CPY in surface waters of the U.S.

The major pathway for exposures to CPY in surface waters is direct accumulation from water, rather than through diet or from sediments. CPY adsorbs strongly to sediments, and this mitigates exposures to benthic invertebrates via sediment. CPY's sediment behavior is consistent with the fact that toxicity is less frequently observed to occur via sediment than water under field testing conditions. The focus of the ERA was thus directed mostly to surface waters and water-column organisms.

Because exposures to CPY in flowing surface waters are episodic with durations usually less than $2 \mathrm{~d}$ (Williams et al. 2014), recovery of organisms between pulses can reduce overall risks, but frequent pulses with short recovery periods could result in cumulative damage and cumulative risks. The few studies that have characterized recovery of the target enzyme (AChE) from CPY suggest that invertebrates recover more rapidly than fish. These recovery periods were from 1 to $\sim 7 \mathrm{~d}$ for invertebrates, and periods of the order of 4-8 wk might be required for complete recovery of $\mathrm{AChE}$ in fish. These periods were considered in the risk assessment. In situations where there is potential for multiple pulsed exposures, a more complex model could be developed that includes accumulation, time to effects and species-specific rates of recovery of AChE. In this assessment of risk, to be conservative, it was assumed that recovery in all organisms would be at the upper bound of observed times (2-8 wk). This assumption likely results in an overestimate of risk.

Characterization of acute toxicity of CPY showed that crustaceans were most sensitive to $\mathrm{CPY}$ ( $\mathrm{HC} 5=0.034 \mu \mathrm{g}$ CPY $\mathrm{L}^{-1}$ ), closely followed by insects $\left(\mathrm{HC} 5=0.087 \mu \mathrm{g} \mathrm{CPY} \mathrm{L}{ }^{-1}\right)$. Fish were less sensitive $\left(\mathrm{HC} 5=0.812 \mu \mathrm{g} \mathrm{CPY} \mathrm{L}{ }^{-1}\right)$. The little data available for aquatic stages of amphibians suggested that they were less sensitive to CPY than fish. Thus fish were protective of amphibians, and amphibians would only need to be considered in an ERA if fish were affected. This was not the case for CPY.

Assessment of the results of a large number of studies of the effects of CPY in cosms suggested that the no observed adverse effect concentration in these systems $\left(\mathrm{NOAEC}_{\mathrm{eco}}\right.$ ) was $0.1 \mu \mathrm{g} \mathrm{L}^{-1}$. These data were derived from single and multiple exposures to CPY and support the conclusion that the HC5s for insects and crustaceans from acute toxicity studies are predictive and protective of toxicity under conditions 
more relevant to the field. Results for cosms thus provided another line of evidence for characterization of the risks of CPY under conditions that are more representative of conditions in the field.

Risks to aquatic organisms from measured exposures were assessed by comparing the 95th centile concentrations to the HC5s for the SSDs. These data may not fully capture peak exposures but suggested that there were de minimis risks for all aquatic organisms from exposures measured after use patterns were changed in 2001. The analyses also showed that risks had decreased from those prior to 2001, which leads to the conclusion that the changes made in 2001 and 2005 to the labeled use patterns, and possibly other changes in general pesticide stewardship, mitigated CPY exposures and reduced risks.

Estimated exposures from models for three focus-scenarios, representing greater vulnerability to exposures than other use scenarios (Williams et al. 2014), allowed the assessment of risks based on 96-h time-weighted-mean concentrations that were matched to the 48-96 h toxicity data. Based on the joint probabilities of distributions of data for exposure and toxicity, we concluded that risks for fish and aquatic stages of insects were de minimis in all three regions. However, in the intensive-use scenario of Orestimba Creek, in California, risk to crustaceans was greater and deemed to be not de minimis. Further analysis of risks from repeated exposures to CPY, in these three focus-scenarios, confirmed the de minimis risks to crustaceans, insects, and fish in the focus-scenarios in GA and MI. Repeated exposures in Orestimba Creek, CA suggested small risks to fish, insects, and crustaceans. We concluded that repeated exposures to insects and crustaceans would not be ecologically relevant because of the potential for rapid recovery in these taxa. Risks for fish may be somewhat greater because there is more uncertainty regarding recovery of the target enzyme AChE and because of their longer reproductive cycles. The lack of fish-kills since 2002 in the U.S. that were associated with confirmed exposure to CPY is consistent with the small risks to fish and the smaller exposures in surface waters since the change in the labeled uses.

Too few data on toxicity of CPYO were available to conduct a probabilistic risk assessment but, on the basis of the available data and the large margins of exposure, we concluded that risks of CPYO to aquatic organisms were de minimis. CPYO is the active metabolite of CPY, and its toxicity is subsumed by the parent CPY. It is thus not surprising that CPYO's toxicity is similar to that of CPY. CPYO is more rapidly hydrolyzed in water and is more polar than CPY and is less likely to be taken up into aquatic organisms. Detections of CPYO in surface waters were infrequent, and the concentrations were all less than toxicologically significant values for the one fish and one invertebrate for which data were available.

This ERA was supported by several strong data-sets. There is a good database of toxicity values for CPY, and many of these tests are of high quality. They are certainly sufficient to characterize acute toxicity to insects, crustaceans, and fish. There are also large sets of data for measured values in surface waters in a number of locations, including areas of intensive use, where greater exposures would be expected. Several studies conducted in cosms, some of excellent quality, are available to provide points of reference for the SSDs and information on recovery of invertebrates 
from exposures to CPY. These strengths have helped reduce uncertainty in the ERA since these cosms included a number of taxa for which there were few toxicity data from laboratory studies. These cosms provide data on responses of aquatic organisms to CPY under realistic conditions.

Just as there were strengths in the ERA there were several areas of uncertainty, some more relevant than others. There were few usable toxicity data from amphibians, but evaluations of the relative sensitivity of fish and amphibians to several classes of toxicants (Weltje et al. 2013) suggest that toxicity data from fish can provide equivalency for amphibians. There were few data on recovery of $\mathrm{AChE}$, the target enzyme for CPY, in aquatic organisms, and this is an uncertainty in the analysis of the relevance of the duration between exposure-events. Because of this, longer and more conservative durations were used in the assessment. In addition, this is an uncertainty that is relevant to all organophosphorus insecticides, as they share the same target enzyme and toxicodynamics of recovery.

There was uncertainty with regard to the demonstrated effects of CPY on behavior and the relevance of these to survival, growth, development, and reproduction (SGDR). Pesticides that target the nervous system are expected to cause effects on behavior, but it is difficult to determine the relevance of these responses to SGDR. For invertebrates in cosms, all responses, including those mediated by behavioral effects, are subsumed into the responses and recovery of exposed populations and communities and are reflected in the $\mathrm{NOAEC}_{\text {eco }}$ of $0.1 \mu \mathrm{g} \mathrm{L}{ }^{-1}$. Data to extrapolate behavioral responses to SGDR for fish and other vertebrates are not available for CPY or, for that matter, all other pesticides that target the nervous system. This is a general uncertainty that has still to be addressed in the science of ERA.

When this ERA was initiated, there was uncertainty about the relevance of the formation of CPYO from the parent, CPY, and how this might influence risks. While still somewhat uncertain, this issue is judged to be of lesser relevance than that of CPY itself. There are several lines of evidence to support this conclusion. The oxon is an integral component of the toxicodynamics of CPY and is formed in vivo. Toxicity of the oxon in aquatic organisms is not vastly or consistently different from that of the parent CPY, and, to some degree is included in the toxicity studies with $\mathrm{CPY}$. The oxon is more rapidly hydrolyzed in the environment, partitions more into water, and is less likely to bioconcentrate into organisms than CPY (see discussions in the companion paper, Mackay et al. 2014).

\section{Summary}

The risk of chlorpyrifos (CPY) to aquatic organisms in surface water of North America was assessed using measured concentrations in surface waters and modeling of exposures to provide daily concentrations that better characterize peak exposures. Ecological effects were compared with results of standard laboratory toxicity tests with single species as well as microcosm and mesocosm studies comprised of complex aquatic communities. The upper 90th centile 96-h concentrations 
(annual maxima) of chlorpyrifos in small streams in agricultural watersheds in Michigan and Georgia were estimated to be $\leq 0.02 \mu \mathrm{g} \mathrm{L}^{-1}$; in a reasonable worstcase California watershed, the 90th centile 96-h annual maximum concentrations ranged from 1.32 to $1.54 \mu \mathrm{g} \mathrm{L}^{-1}$. Measured concentrations of chlorpyrifos are less than estimates from simulation models. The 95th centile for more than 10,000 records compiled by the US Geological Survey was $0.008 \mu \mathrm{g} \mathrm{L}^{-1}$. Acute toxicity endpoints for 23 species of crustaceans ranged from 0.035 to $457 \mu \mathrm{g} \mathrm{L} \mathrm{L}^{-1}$; for 18 species of aquatic insects, from 0.05 to $27 \mu \mathrm{g} \mathrm{L}^{-1}$; and for 25 species of fish, from 0.53 to $>806 \mu \mathrm{g} \mathrm{L}^{-1}$. The No Observed Adverse Effect Concentration $\left(\mathrm{NOAEC}_{\mathrm{eco}}\right)$ in more than a dozen microcosm and mesocosm studies conducted in a variety of climatic zones, was consistently $0.1 \mu \mathrm{g} \mathrm{L}^{-1}$. These results indicated that concentrations of CPY in surface waters are rarely great enough to cause acute toxicity to even the most sensitive aquatic species. This conclusion is consistent with the lack of fishkills reported for CPY's normal use in agriculture in the U.S.

Analysis of measured exposures showed that concentrations in surface waters declined after labeled use-patterns changed in 2001, and resulted in decreased risks for crustaceans, aquatic stages of insects, and fish. Probabilistic analysis of 96-h time-weighted mean concentrations, predicted by use of model simulation for three focus-scenarios selected for regions of more intense use of CPY and vulnerability to runoff, showed that risks from individual and repeated exposures to CPY in the Georgia and Michigan watersheds were de minimis. Risks from individual exposures in the intense-use scenario from California were de minimis for fish and insects and low for crustaceans. Risks from repeated exposures in the California intense-use scenario were judged not to be ecologically relevant for insects and fish, but there were some risks to crustaceans. Limited data show that chlorpyrifos oxon (CPYO), the active metabolite of CPY is of similar toxicity to the parent compound. Concentrations of CPYO in surface waters are smaller than those of CPY and less frequently detected. Risks for CPYO in aquatic organisms were judged to be de minimis.

Several uncertainties common to all AChE inhibitors were identified. Insufficient data were available to allow interpretation of the relevance of effects of CPY (and other pesticides that also target $\mathrm{AChE}$ ) on behavior to assessment endpoints such as survival, growth, development, and reproduction. Data on the recovery of AChE from inhibition by CPY in fish are limited. Such data are relevant to the characterization of risks from repeated exposures, and represent an uncertainty in the assessment of risks for CPY and other pesticides that share the same target and toxicodynamics. More intensive monitoring of areas of greater use and more comprehensive models of cumulative effects that include rates of accumulation, metabolism and recovery of $\mathrm{AChE}$ in the more sensitive species would be useful in reducing this uncertainty.

Acknowledgements We wish to thank Julie Anderson for assistance with review and collation of the toxicity data. We thank the anonymous reviewers of this paper for their suggestions and constructive criticism. Prof. Giesy was supported by the Canada Research Chair program, a Visiting Distinguished Professorship in the Department of Biology and Chemistry and State Key Laboratory 
in Marine Pollution, City University of Hong Kong, the 2012 "High Level Foreign Experts" (\#GDW20123200120) program, funded by the State Administration of Foreign Experts Affairs, the P.R. China to Nanjing University and the Einstein Professor Program of the Chinese Academy of Sciences. Funding for this project was provided by Dow AgroSciences.

Open Access This chapter is distributed under the terms of the Creative Commons Attribution Noncommercial License, which permits any noncommercial use, distribution, and reproduction in any medium, provided the original author(s) and source are credited.

\section{References}

Amweg EL, Weston DP, You J, Lydy MJ (2006) Pyrethroid insecticides and sediment toxicity in urban creeks from California and Tennessee. Environ Sci Technol 40:1700-1706

Ankley GT, Call DJ, Cox JS, Kahl MD, Hoke RA, Kosian PA (1994) Organic carbon partitioning as a basis for predicting the toxicity of chlorpyrifos in sediments. Environ Toxicol Chem 13:621-626

Banks KE, Hunter DH, Wachal DJ (2005) Chlorpyrifos in surface waters before and after a federally mandated ban. Environ Int 31:351-356

Barata C, Solayan A, Porte C (2004) Role of B-esterases in assessing toxicity of organophosphorus (chlorpyrifos, malathion) and carbamate (carbofuran) pesticides to Daphnia magna. Aquat Toxicol 66:125-139

Barron MG, Woodburn KB (1995) Ecotoxicology of chlorpyrifos. Rev Environ Contam Toxicol 144:1-93

Bernabo I, Gallo L, Sperone E, Tripepi S, Brunelli E (2011) Survival, development, and gonadal differentiation in Rana dalmatina chronically exposed to chlorpyrifos. J Exp Zool A Ecol Genet Physiol 315:314-327

Biever RC, Giddings JM, Kiamos M, Annunziato MF, Meyerhoff R, Racke K (1994) Effects of chlorpyrifos on aquatic microcosms over a range of off-target spray drift exposure levels. In: BCPC (ed.) Proceedings, Brighton Crop Protection Conference on Pests and Diseases. Vol. 3, BCPC, London, UK. pp 1367-1372

Bogen KT, Reiss R (2012) Generalized Haber's law for exponential concentration decline, with application to riparian-aquatic pesticide ecotoxicity. Risk Anal 32:250-258

Boone JS, Chambers JE (1996) Time course of inhibition of cholinesterase and aliesterase activities, and nonprotein sulfhydryl levels following exposure to organophosphorus insecticides in mosquitofish (Gambusia affinis). Fundam Appl Toxicol 29:202-207

Brazner JC, Kline ER (1990) Effects of chlorpyrifos on the diet and growth of larval fathead minnows, Pimephales promelas in littoral enclosures. Can J Fish Aquat Sci 47:1157-1165

Brock TCM, Arts GHP, Maltby L, van den Brink PJ (2006) Aquatic risks of pesticides, ecological protection goals and common aims in EU legislation. Integr Environ Assess Manag 2:e20-e46

Brock TCM, Bogaert M, Bos AR, Breukelen SWF, Reiche R, Terwoert J, Suykerbuyk REM, Roijackers RMM (1992) Fate and effects of the insecticide Dursban ${ }^{\circledR} 4 \mathrm{E}$ in indoor Elodea dominated and macrophyte-free freshwater model ecosystems: II. Secondary effects on community structure. Arch Environ Contam Toxicol 23:391-409

Brock TCM, Roijackers RMM, Rollon R, Bransen F, van der Heyden L (1995) Effects of nutrient loading and insecticide application on the ecology of Elodea-dominated freshwater microcosms: II. Responses of macrophytes, periphyton and macroinvertebrate grazers. Arch Hydrobiol 134:53-74

Brock TCM, Van Wijngaarden RPA, Van Geest GJ (2000) Ecological risks of pesticides in freshwater ecosystems. Part 2: Insecticides. Alterra, Wageningen, The Netherlands, 089

Brock TCM, Vet JJRM, Kerkhofs MJJ, Lijzen J, Zuilekom WJ, Gijlstra R (1993) Fate and effects of the insecticide Dursban ${ }^{\circledast} 4 \mathrm{E}$ in indoor Elodea dominated and macrophyte-free freshwater 
model ecosystems: III. Aspects of ecosystem functioning. Arch Environ Contam Toxicol 25: $160-169$

CCME (2008) Canadian water quality guidelines for the protection of aquatic life —chlorpyrifos. Canadian Council of Ministers of the Environment, Ottawa, ON, Canada. http://ceqg-reqe. ccme.ca/download/en/164

CCME (2007) Canadian water quality guidelines for the protection of aquatic life. A protocol for the derivation of water quality guidelines for the protection of aquatic life 2007. Canadian Council of Ministers of the Environment, Ottawa, ON, Canada. http://ceqg-rcqe.ccme.ca/

CCME (2013) Determination of hazardous concentrations with species sensitivity distributions, SSD Master. Canadian Council of Ministers of the Environment, Ottawa, ON, Canada

CDPR (2012) Surface water database. California Department of Pesticide Regulation. http://www. cdpr.ca.gov/docs/emon/surfwtr/surfcont.htm. Accessed 24 Feb 2012

Chandrasekera LK, Pathiratne A (2005) Response of brain and liver cholinesterases of Nile tilapia, Oreochromis niloticus, to single and multiple exposures of chlorpyrifos and carbosulfan. Bull Environ Contam Toxicol 75:1228-1233

Cuppen JGM, Gylstra R, Sv B, Budde BJ, Brock TCM (1995) Effects of nutrient loading and insecticide application on the ecology of Elodea-dominated freshwater microcosms: responses of macroinvertebrate detritivores, breakdown of plant litter, and final conclusions. Arch Hydrobiol 134:157-177

Cutler GC, Purdy J, Giesy JP, Solomon KR (2014) Risk to pollinators from the use of chlorpyrifos in the United States. Rev Environ Contam Toxicol 231:219-265

Daam MA, Crum SJ, Van den Brink PJ, Nogueira AJ (2008a) Fate and effects of the insecticide chlorpyrifos in outdoor plankton-dominated microcosms in Thailand. Environ Toxicol Chem 27:2530-2538

Daam MA, Van den Brink PJ, Nogueira AJ (2008b) Impact of single and repeated applications of the insecticide chlorpyrifos on tropical freshwater plankton communities. Ecotoxicology 17:756-771

De Silva PM, Samayawardhena LA (2005) Effects of chlorpyrifos on reproductive performances of guppy (Poecilia reticulata). Chemosphere 58:1293-1299

Ding Y, Harwood AD, Foslund HM, Lydy MJ (2010) Distribution and toxicity of sedimentassociated pesticides in urban and agricultural waterways from Illinois, USA. Environ Toxicol Chem 29:149-157

Domingues I, Guilhermino L, Soares AM, Nogueira AJ, Monaghan KA (2009) Influence of exposure scenario on pesticide toxicity in the midge Kiefferulus calligaster (Kieffer). Ecotoxicol Environ Saf 72:450-457

ECOFRAM (1999) ECOFRAM aquatic final draft reports. United States Environmental Protection Agency, Washington, DC. http://www.epa.gov/oppefed1/ecorisk/aquareport.pdf

Ensminger M, Bergin R, Spurlock F, Goh KS (2011) Pesticide concentrations in water and sediment and associated invertebrate toxicity in Del Puerto and Orestimba Creeks, California, 2007-2008. Environ Monit Assess 175:573-587

Giddings JM (1993a) Chlorpyrifos (Lorsban 4E): outdoor aquatic microcosm test for environmental fate and ecological effects. Springborn Laboratories for Dow Chemical, Wareham, MA (unpublished report)

Giddings JM (1993b) Chlorpyrifos (Lorsban 4E): outdoor aquatic microcosm test for environmental fate and ecological effects of combinations of spray and slurry treatments. Springborn Laboratories for Dow Chemical, Wareham, MA (unpublished report)

Giddings JM (2011) Invertebrate communities in outdoor microcosms treated with chlorpyrifos: reanalysis of data reported in Giddings 1992. Dow AgroSciences, Indianapolis, IN (unpublished report)

Giddings JM, Biever RC, Racke KD (1997) Fate of chlorpyrifos in outdoor pond microcosms and effects on growth and survival of bluegill sunfish. Environ Toxicol Chem 16:2353-2362

Giesy JP, Geiger RA (1980) Large scale microcosms for assessing fates and effects of trace contaminants. In: Giesy JP (ed) Microcosms in ecological research. Department of Energy, Technical Information Center, Oak Ridge, TN, pp 304-318 
Giesy JP, Odum EP (1980) Microcosmology: the theoretical basis. In: Giesy JP (ed) Microcosms in ecological research. Department of Energy Technical Information Center, Oak Ridge, TN, pp 1-13

Giesy JP, Solomon KR, Coates JR, Dixon KR, Giddings JM, Kenaga EE (1999) Chlorpyrifos: ecological risk assessment in North American aquatic environments. Rev Environ Contam Toxicol 160:1-129

Graney RA, Giesy JP, DiToro D (1989) Mesocosm experimental design strategies: advantages and disadvantages in ecological risk assessment. In: Voshell JR Jr (ed) Using mesocosms to assess the aquatic ecological risk of pesticides: theory and practice. Entomological Society of America, Lanham, MD, pp 74-88

Graney RL, Giesy JP, Clark JR (1995) Field studies. In: Rand GM (ed) Fundamentals of aquatic toxicology: effects, environmental fate and risk assessment. Taylor \& Francis, Bristol, PA, pp 257-305

Hall L Jr, Anderson RD (2012) Historical trends analysis of 2004 to 2009 toxicity and pesticide data for California's Central Valley. J Environ Sci Health A 47:801-811

Hurlburt SH, Mulla MS, Keith JO, Westlake WE, Dhsch ME (1970) Biological effects and persistence of Dursban in freshwater ponds. J Econ Entomol 63:43-52

Hurlburt SH, Mulla MS, Willson HR (1972) Effects of an organophosphorus insecticide on the phytoplankton, zooplankton and insect populations of fresh-water ponds. Ecol Monogr 42:269-299

Kavitha P, Rao JV (2008) Toxic effects of chlorpyrifos on antioxidant enzymes and target enzyme acetylcholinesterase interaction in mosquito fish, Gambusia affinis. Environ Toxicol Pharmacol 26:192-198

Klimisch H-J, Andreae M, Tillmann U (1997) A systematic approach for evaluating the quality of experimental toxicological and ecotoxicological data. Regul Toxicol Pharmacol 25:1-5

Kumar A, Doan H, Barnes M, Chapman JC, Kookana RS (2010) Response and recovery of acetylcholinesterase activity in freshwater shrimp, Paratya australiensis (Decapoda: Atyidae) exposed to selected anti-cholinesterase insecticides. Ecotoxicol Environ Saf 73:1503-1510

Laetz CA, Baldwin DH, Collier TK, Hebert V, Stark JD, Scholz NL (2009) The synergistic toxicity of pesticide mixtures: implications for risk assessment and the conservation of endangered Pacific salmon. Environ Health Perspect 117:348-353

Leeuwangh P (1994) Comparison of chlorpyrifos fate and effects in outdoor aquatic micro-and mesocosms of various scale and construction. In: Hill IR, Heimbach F, Leeuwangh P, Matthiesen P (eds) Freshwater field tests for hazard assessment of chemicals. Lewis Publishers, Boca Raton, FL, pp 217-248

LeNoir JS, McConnell LL, Fellers GM, Cahill TM, Seiber JN (1999) Summertime transport of current-use pesticides from California's Central Valley to the Sierra Nevada mountain range, USA. Environ Toxicol Chem 18:2715-2722

López-Mancisidor P, Carbonell G, Fernandez C, Tarazona JV (2008a) Ecological impact of repeated applications of chlorpyrifos on zooplankton community in mesocosms under Mediterranean conditions. Ecotoxicology 17:811-825

López-Mancisidor P, Carbonell G, Marina A, Fernandez C, Tarazona JV (2008b) Zooplankton community responses to chlorpyrifos in mesocosms under Mediterranean conditions. Ecotoxicol Environ Saf 71:16-25

Mackay D, Giesy JP, Solomon KR (2014) Fate in the environment and long-range atmospheric transport of the organophosphorus insecticide, chlorpyrifos and its oxon. Rev Environ Contam Toxicol 231:35-76

Maltby L, Blake NN, Brock TCM, van den Brink PJ (2005) Insecticide species sensitivity distributions: the importance of test species selection and relevance to aquatic ecosystems. Environ Toxicol Chem 24:379-388

Metcalf RL, Sanborn JR (1975) Pesticides and environmental quality in Illinois. Ill Nat Hist Surv Bull 31:381-436

Metcalf RL, Sanga GK, Kapoor IP (1971) Model ecosystems for the evaluation of pesticide biodegradability and ecological magnification. Environ Sci Technol 5:709-713 
Moore DRJ, Teed RS, Greer C, Solomon KR, Giesy JP (2014) Refined avian risk assessment for chlorpyrifos in the United States. Rev Environ Contam Toxicol 231:163-217

Moore DRJ, Fischer DL, Teed RS, Rodney SI (2010) Probabilistic risk-assessment model for birds exposed to granular pesticides. Integr Environ Assess Manag 6:260-272

Moore DRJ, Teed RS (2012) Risks of carbamate and organophosphate pesticide mixtures to salmon in the Pacific Northwest. Integr Environ Assess Manag 9(1):70-78

Morgan MJ, Fancey LL, Kiceniuk JW (1990) Response and recovery of brain acetylcholinesterase activity in Atlantic salmon Salmo salar exposed to fenitrothion. Can J Fish Aquat Sci 47: $1652-1654$

Naddy RB, Johnson KA, Klaine SJ (2000) Response of Daphnia magna to pulsed exposures of chlorpyrifos. Environ Toxicol Chem 19:423-431

Naddy RB, Klaine SJ (2001) Effect of pulse frequency and interval on the toxicity of chlorpyrifos to Daphnia magna. Chemosphere 45:497-506

NASQAN (2012) USGS national stream quality accounting network. United States Geological Survey. http://water.usgs.gov/nasqan/. Accessed $24 \mathrm{Feb} 2012$

NAWQA (2012) USGS national water quality assessment data warehouse. United States Geological Survey. http://infotrek.er.usgs.gov/apex/f?p=NAWQA:HOME:0. Accessed 24 Feb 2012

Phillips BM, Anderson BS, Hunt JW, Huntley SA, Tjeerdema RS, Kapellas N, Worcester K (2006) Solid-phase sediment toxicity identification evaluation in an agricultural stream. Environ Toxicol Chem 25:1671-1676

Phillips BM, Anderson BS, Hunt JW, Siegler K, Voorhees JP, Tjeerdema RS, McNeill K (2012) Pyrethroid and organophosphate pesticide-associated toxicity in two coastal watersheds (California, USA). Environ Toxicol Chem 31:1595-1603

Phillips PJ, Ator SW, Nystrom EA (2007) Temporal changes in surface-water insecticide concentrations after the phase out of diazinon and chlorpyrifos. Environ Sci Technol 41:4246-4251

Posthuma L, Suter GW, Traas T (2002) Species sensitivity distributions in risk assessment, species sensitivity distributions in ecotoxicology. CRC, Boca Raton, FL, 564

Pusey BJ, Arthrington A, McLean J (1994) The effects of a pulsed application of chlorpyrifos on macroinvertebrate communities in an outdoor artificial stream system. Ecotoxicol Environ Saf 27:221-250

Rao JV, Begum G, Pallela R, Usman PK, Rao RN (2005) Changes in behavior and brain acetylcholinesterase activity in mosquito fish, Gambusia affinis in response to the sub-lethal exposure to chlorpyrifos. Int J Environ Res Pub Health 2:478-483

Richards SM, Kendall RJ (2002) Biochemical effects of chlorpyrifos on two developmental stages of Xenopus laevis. Environ Toxicol Chem 21:1826-1835

Sandahl JF, Baldwin DH, Jenkins JJ, Scholz NL (2005) Comparative thresholds for acetylcholinesterase inhibition and behavioral impairment in coho salmon exposed to chlorpyrifos. Environ Toxicol Chem 24:136-145

Sandahl JF, Baldwin DH, Jenkins JJ, Scholz NL (2004) Odor-evoked field potentials as indicators of sublethal neurotoxicity in juvenile coho salmon (Oncorhynchus kisutch) exposed to copper, chlorpyrifos, or esfenvalerate. Can J Fish Aquat Sci 61:404-413

Satapornvanit K, Baird DJ, Little DC (2009) Laboratory toxicity test and post-exposure feeding inhibition using the giant freshwater prawn Macrobrachium rosenbergii. Chemosphere 74: $1209-1215$

Siefert RE, Lozano SJ, Brazner JC, Knuth ML (1989) Littoral enclosures for aquatic field testing of pesticides: effects of chlorpyrifos on a natural system. In: Voshell JR Jr (ed) Using mesocosms to assess the aquatic ecological risk of pesticides: theory and practice. Entomological Society of America, Lanham, MD, pp 57-73

Solomon KR, Williams WM, Mackay D, Purdy J, Giddings JM, Giesy JP (2014) Properties and uses of chlorpyrifos in the United States. Rev Environ Contam Toxicol 231:13-34

Tierney K, Casselman M, Takeda S, Farrell T, Kennedy C (2007) The relationship between cholinesterase inhibition and two types of swimming performance in chlorpyrifos-exposed coho salmon (Oncorhynchus kisutch). Environ Toxicol Chem 26:998-1004 
Tilton FA, Bammler TK, Gallagher EP (2011) Swimming impairment and acetylcholinesterase inhibition in zebrafish exposed to copper or chlorpyrifos separately, or as mixtures. Comp Biochem Physiol C 153:9-16

USEPA (2012a) Aggregate incident summary report by ingredient for the date range 01/01/2002 to 06/15/2012. United States Environmental Protection Agency Office of Pesticide Programs, Washington, DC

USEPA (2007) ECOTOXicology Database System. Version 4.0. United States Environmental Protection Agency, Office of Pesticide Programs, Environmental Fate and Effects Division, United States EPA, Washington, D. http://www.epa.gov/ecotox/. Accessed March 2012

USEPA (1992) Framework for ecological risk assessment. United States Environmental Protection Agency, Washington, DC, EPA/630/R-92/001

USEPA (1998) Guidelines for ecological risk assessment. United States Environmental Protection Agency, Washington, DC

USEPA (2004) Overview of the ecological risk assessment process in the office of pesticide programs: endangered and threatened species effects determinations. United States Environmental Protection Agency, Office of Prevention, Pesticides, and Toxic Substances, Office of Pesticide Programs, Washington, DC

USEPA (2008) Registration review - preliminary problem formulation for ecological risk and environmental fate, endangered species and drinking water assessments for chlorpyrifos. United States Environmental Protection Agency, Office of Pesticide Programs, Washington, DC

USEPA (2012b) Specified ingredient incidents for the date range 01/01/2002 to 06/15/2012. United States Environmental Protection Agency, Office of Pesticide Programs, Washington, DC

van den Brink PJ, Ev D, Gylstra R, Crum SJH, Brock TCM (1995) Effects of chronic low concentrations of the pesticides chlorpyrifos and atrazine in indoor freshwater microcosms. Chemosphere 31:3181-3200

van den Brink PJ, Van Wijngaarden RPA, Lucassen WGH, Brock TCM, Leeuwangh P (1996) Effects of the insecticide Dursban ${ }^{\circledast} 4 \mathrm{E}$ (active ingredient chlorpyrifos) in outdoor experimental ditches: II. Invertebrate community responses and recovery. Environ Toxicol Chem 15:1143-1153

van der Wel H, Welling W (1989) Inhibition of acetylcholinesterase in guppies (Poecilia reticulata) by chlorpyrifos at sublethal concentrations: methodological aspects. Ecotoxicol Environ Saf 17:205-215

Van Donk E, Prins H, Voogd HM, Crum SJH, Brock TCM (1995) Effects of nutrient loading and insecticide application on the ecology of Elodea-dominated freshwater microcosms: I. Responses of plankton and zooplanktivorous insects. Arch Hydrobiol 133:417-439

van Wijngaarden RP, Brock TC, Douglas MT (2005a) Effects of chlorpyrifos in freshwater model ecosystems: the influence of experimental conditions on ecotoxicological thresholds. Pest Manag Sci 61:923-935

van Wijngaarden RPA, Brink PJ, Crum SJH, Oude Voshaar JH, Brock TCM, Leeuwangh P (1996) Effects of the insecticide Dursban ${ }^{\circledR} 4 \mathrm{E}$ (active ingredient chlorpyrifos) in outdoor experimental ditches: II. Invertebrate community responses and recovery. Environ Toxicol Chem 15: $1133-1142$

van Wijngaarden RPA, Brock TCM, van den Brink PJ (2005b) Threshold levels of insecticides in freshwater ecosystems, a review. Ecotoxicology 14:353-378

Varo I, Serrano R, Pitarch E, Amat F, Lopez FJ, Navarro JC (2002) Bioaccumulation of chlorpyrifos through an experimental food chain: study of protein HSP70 as biomarker of sublethal stress in fish. Arch Environ Contam Toxicol 42:229-235

Ward S, Arthington AH, Pusey BJ (1995) The effects of a chronic application of chlorpyrifos on the macroinvertebrate fauna in an outdoor artificial stream system: species responses. Ecotoxicol Environ Saf 30:2-23

WDOE (2012) Environmental information management database. Washington State Department of Ecology. http://www.ecy.wa.gov/eim/. Accessed 3 Apr 2012

Weltje L, Simpson P, Gross M, Crane M, Wheeler JR (2013) Comparative acute and chronic sensitivity of fish and amphibians: a critical review of data. Environ Toxicol Chem 32(5):984-994 
Weston DP, Ding Y, Zhang M, Lydy MJ (2012) Identifying the cause of sediment toxicity in agricultural sediments: the role of pyrethroids and nine seldom-measured hydrophobic pesticides. Chemosphere 90:958-964

Widder PD, Bidwell JR (2006) Cholinesterase activity and behavior in chlorpyrifos-exposed Rana sphenocephala tadpoles. Environ Toxicol Chem 25:2446-2454

Williams WM, Giddings JM, Purdy J, Solomon KR, Giesy JP (2014) Exposures of aquatic organisms resulting from the use of chlorpyrifos in the United States. Rev Environ Contam Toxicol 231:77-118

Williamson CE, Butler NM (1986) Predation on rotifers by the suspension-feeding calanoid copepod Diaptomus pallidus. Limnol Oceanogr 31:393-402

Zafar MI, Van Wijngaarden RP, Roessink I, Van den Brink PJ (2011) Effects of time-variable exposure regimes of the insecticide chlorpyrifos on freshwater invertebrate communities in microcosms. Environ Toxicol Chem 30:1383-1394 